\title{
Vortex Diode Analysis and Testing for Fluoride Salt-Cooled High-Temperature Reactors
}

September 2011

Prepared by

Graydon L. Yoder, Jr.

Oak Ridge National Laboratory

Yousri Elkassabgi, Gerardo De Leon, Catlin Fetterly, Jorge Ramos, and James Robbins

Texas A\&M University, Kingsville, TX

R. Burns Cunningham

University of Tennessee, Knoxville, TN

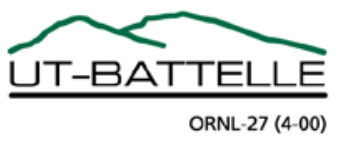




\title{
DOCUMENT AVAILABILITY
}

Reports produced after January 1, 1996, are generally available free via the U.S. Department of Energy (DOE) Information Bridge.

Web site http://www.osti.gov/bridge

Reports produced before January 1, 1996, may be purchased by members of the public from the following source.

\author{
National Technical Information Service \\ 5285 Port Royal Road \\ Springfield, VA 22161 \\ Telephone 703-605-6000 (1-800-553-6847) \\ TDD 703-487-4639 \\ Fax 703-605-6900 \\ E-mail info@ntis.gov \\ Web site http://www.ntis.gov/support/ordernowabout.htm
}

Reports are available to DOE employees, DOE contractors, Energy Technology Data Exchange (ETDE) representatives, and International Nuclear Information System (INIS) representatives from the following source.

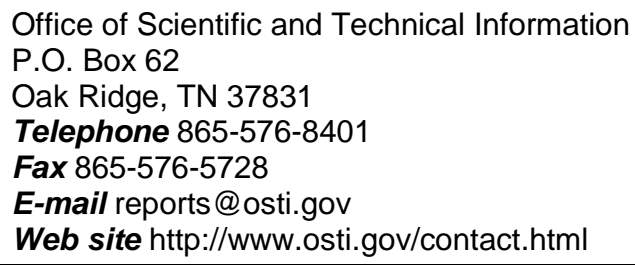

This report was prepared as an account of work sponsored by an agency of the United States Government. Neither the United States Government nor any agency thereof, nor any of their employees, makes any warranty, express or implied, or assumes any legal liability or responsibility for the accuracy, completeness, or usefulness of any information, apparatus, product, or process disclosed, or represents that its use would not infringe privately owned rights. Reference herein to any specific commercial product, process, or service by trade name, trademark, manufacturer, or otherwise, does not necessarily constitute or imply its endorsement, recommendation, or favoring by the United States Government or any agency thereof. The views and opinions of authors expressed herein do not necessarily state or reflect those of the United States Government or any agency thereof. 
Reactor and Nuclear Systems Division

\title{
VORTEX DIODE ANALYSIS AND TESTING FOR FLUORIDE SALT -COOLED HIGH-TEMPERATURE REACTORS
}

\author{
Graydon L. Yoder, Jr. \\ Oak Ridge National Laboratory \\ Yousri Elkassabgi, Gerardo De Leon, Catlin Fetterly, Jorge Ramos, and James Robbins \\ Texas A\&M University \\ R. Burns Cunningham \\ University of Tennessee, Knoxville, TN
}

September 2011

Prepared by

OAK RIDGE NATIONAL LABORATORY

Oak Ridge, Tennessee 37831-6283

managed by

UT-BATTELLE, LLC

for the

U.S. DEPARTMENT OF ENERGY

under contract DE-AC05-00OR22725 



\section{CONTENTS}

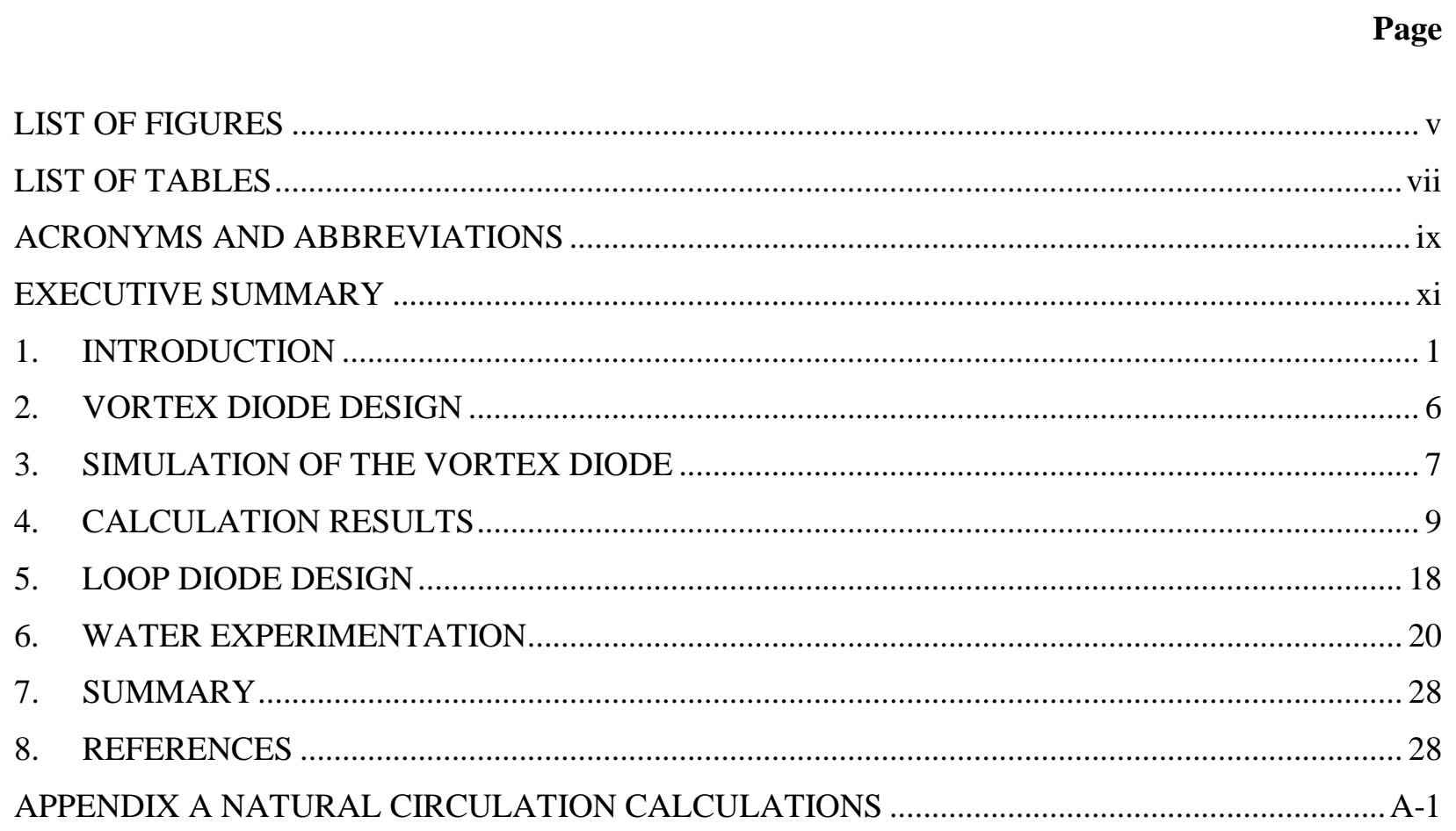





\section{LIST OF FIGURES}

Figure

Page

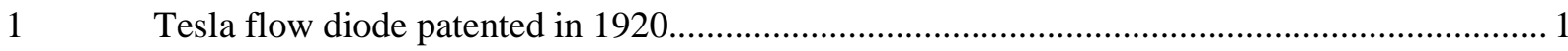

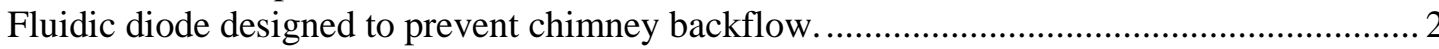

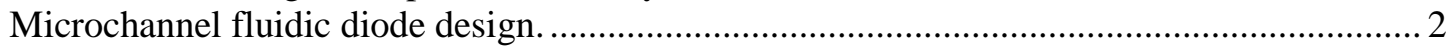

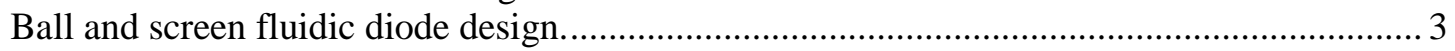

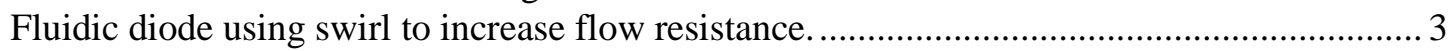

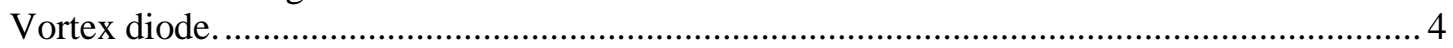

Pumping system with no moving parts using vortex diodes (NuVision).............................. 4

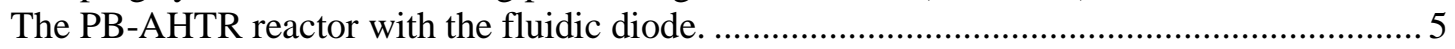

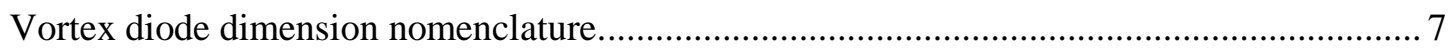

Typical vortex diode configuration meshed with GAMBIT. ................................................ 8

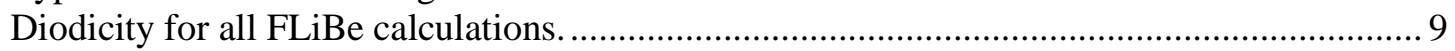

Drawing of $171.4 \mathrm{~mm}$ diode with enhanced design features. ............................................... 13

Diodicity versus Reynolds number for $228.6 \mathrm{~mm}$ and $304.8 \mathrm{~mm}$ diodes. ............................. 14

Euler number in reverse direction versus Reynolds number for $228.6 \mathrm{~mm}$ and

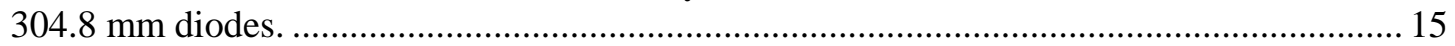

15 Euler number in forward direction versus Reynolds number for $228.6 \mathrm{~mm}$ and

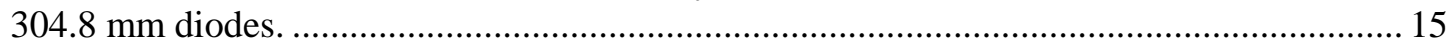

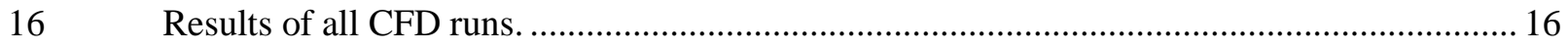

17 Path lines of static pressure for FLiBe salt for a static pressure drop of $426 \mathrm{kPa}$ in

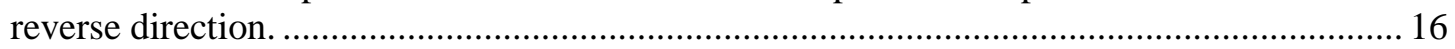

18 Path lines of static pressure for FLiBe salt for a static pressure drop of $421 \mathrm{kPa}$ in

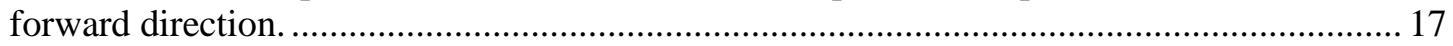

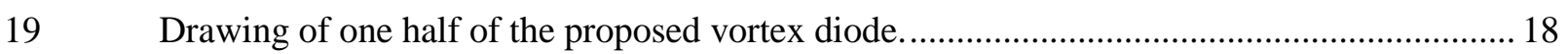

20 Overall view of the ORNL Liquid Salt Flow Loop............................................................. 19

21 ORNL Liquid Salt Flow Loop showing test section piping to be replaced by the flow

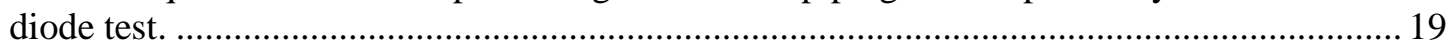

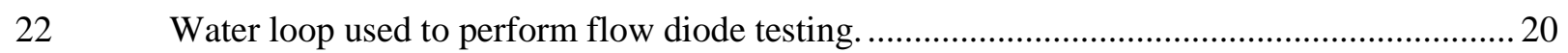

23 Bell and Gossett pump curve (216 mm impeller used in testing). .......................................... 21

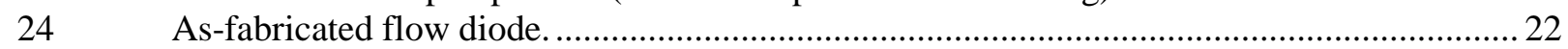

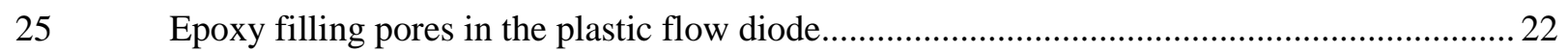

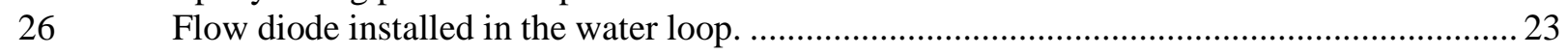

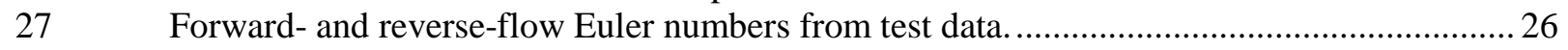

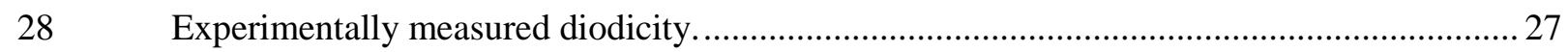

29 Comparison of experimental data and CFD predictions. ................................................... 27 



\section{LIST OF TABLES}

Table

Page

1 Results of FLUENT analysis for three diode designs using FLiBe as the fluid..................... 10

2 Results of FLUENT analysis for four different diode designs using FLiNaK as the fluid ..... 12

3 Results of FLUENT analysis for a single diode design using water as the fluid .................... 12

$4 \quad$ Effect of mesh size (number of cells) ................................................................................. 13

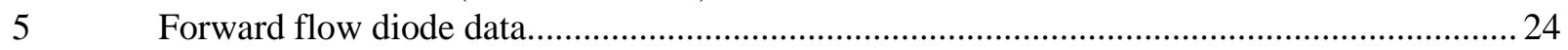

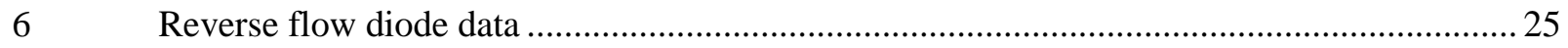





\section{ACRONYMS AND ABBREVIATIONS}

CFD computational fluid dynamics

DHX DRACS salt-to-salt heat exchanger

DRACS direct reactor auxiliary cooling system

FHR fluoride salt-cooled high-temperature reactor

ID inner diameter

LES large eddy simulation

ORNL Oak Ridge National Laboratory

PB-AHTR Pebble Bed Advanced High Temperature Reactor 



\section{EXECUTIVE SUMMARY}

Fluidic diodes are presently being considered for use in several fluoride salt-cooled high-temperature reactor designs. A fluidic diode is a passive device that acts as a leaky check valve. These devices are installed in emergency heat removal systems that are designed to passively remove reactor decay heat using natural circulation. The direct reactor auxiliary cooling system (DRACS) uses DRACS salt-to-salt heat exchangers (DHXs) that operate in a path parallel to the core flow. Because of this geometry, under normal operating conditions some flow bypasses the core and flows through the DHX. A flow diode, operating in reverse direction, is-used to minimize this flow when the primary coolant pumps are in operation, while allowing forward flow through the DHX under natural circulation conditions. The DRACSs reject the core decay heat to the environment under loss-of-flow accident conditions and as such are a reactor safety feature. Fluidic diodes have not previously been used in an operating reactor system, and therefore their characteristics must be quantified to ensure successful operation. This report parametrically examines multiple design parameters of a vortex-type fluidic diode to determine the size of diode needed to reject a particular amount of decay heat. Additional calculations were performed to size a scaled diode that could be tested in the Oak Ridge National Laboratory Liquid Salt Flow Loop. These parametric studies have shown that a $152.4 \mathrm{~mm}$ diode could be used as a test article in that facility. A design for this diode is developed, and changes to the loop that will be necessary to test the diode are discussed.

Initial testing of a scaled flow diode has been carried out in a water loop. The $150 \mathrm{~mm}$ diode design discussed above was modified to improve performance, and the final design tested was a $171.45 \mathrm{~mm}$ diameter vortex diode. The results of this testing indicate that diodicities of about 20 can be obtained for diodes of this size. Experimental results show similar trends as the computational fluid dynamics (CFD) results presented in this report; however, some differences exist that will need to be assessed in future studies. The results of this testing will be used to improve the diode design to be tested in the liquid salt loop system. 



\section{INTRODUCTION}

Fluidic diodes are used as flow control devices; they act as a leaky check valves. They offer high resistance to flow in one direction and much smaller resistance in the opposite direction. They accomplish this task without any moving parts, which makes them reliable and dependable. ${ }^{1}$ Flow diode concepts have been around for many years. Figure 1 shows a fluidic diode patented by Tesla in $1920,{ }^{2}$ and many variations have since been patented. Tesla's design is such that the flow splits and recombines several times in the high-resistence flow direction, while flow is relatively straight in the low-resistance direction.

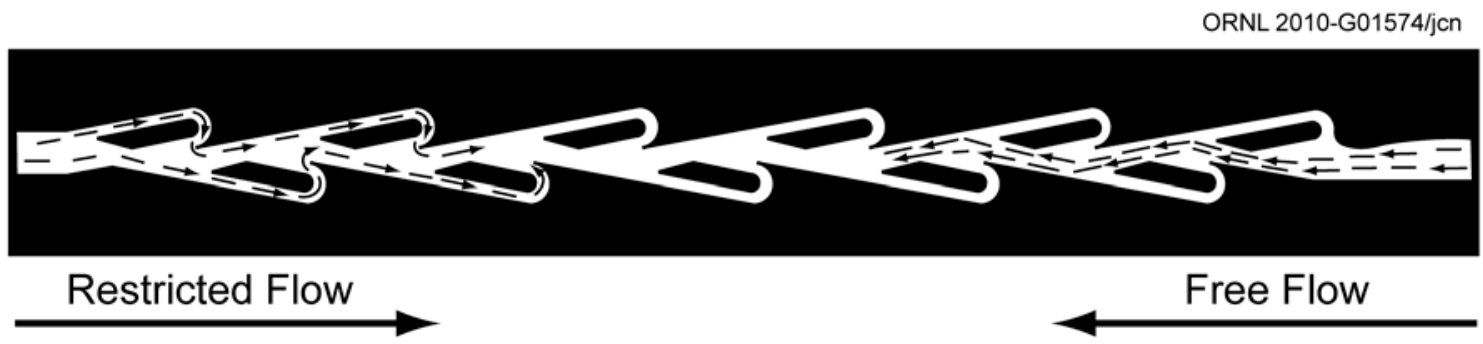

Fig. 1. Tesla flow diode patented in 1920. (US Patent 1,329,559)

Some additional examples are shown in Figs. 2 through 5. Figure 2 shows a flow diode design based on multiple expansions and contractions. The figure is from a patent designed to prevent downflow in a chimney. Flow in the upward, or forward, direction moves through one tapered contraction, and then exhausts through a series of continuously larger openings. In reverse flow (or a chimney downdraft), the flow passes through smaller and smaller sudden contractions, and the flow resistance in this direction is much larger. Figure 3 shows a microchannel fluidic diode. The diode is the chain of arrows in the center of the figure. The remainder of the structure is used to measure pressures at either end of the diode. In this design the higher flow resistance is in the right-to-left direction, and the lower flow resistance in the leftto-right one. A ball-and-screen diode design is shown in Fig. 4. In this design the balls need to be close to buoyant in the flow stream. On the left figure, the flow is in the upward direction. In this case the balls are captured by a screen that has a relatively large opening cross section compared to the cross section of the balls, and the flow is only slightly restricted by the presence of the balls. In the downward direction, the balls are restricted by a much smaller cross section, and the flow must pass through a packed bed geometry leading to significantly higher flow resistance. Another fluidic diode design is shown in Fig. 5 . A series of guide blades are centered in a flow tube, and a swirl-inducing impeller is located at one end of the device. In the figure flow in the downward direction is primarily through the unobstructed annular region around the guide blades; this direction is the low-pressure drop direction. Flow in the upward direction must first flow through the impeller, which initiates swirl in the flow. The guide blades are designed to force the flow to continue swirling through the length of the device, causing a high-pressure drop in that direction.

Another type of fluidic diode design also uses swirling flow in a somewhat different configuration; the vortex diode is designed to create a rotating flow to increase the flow resistance in one direction. An example of the vortex diode is shown in Fig. 6. It is designed so that flow in the forward direction enters at the center of the device and exits at the tangential port (the diagram on the right of Fig. 6). In the reverse direction, flow enters the tangential port, induces a swirling flow in the diode and then exits at the center port (shown in the left-hand diagram of Fig. 6), increasing the pressure drop significantly over that in the forward direction. 


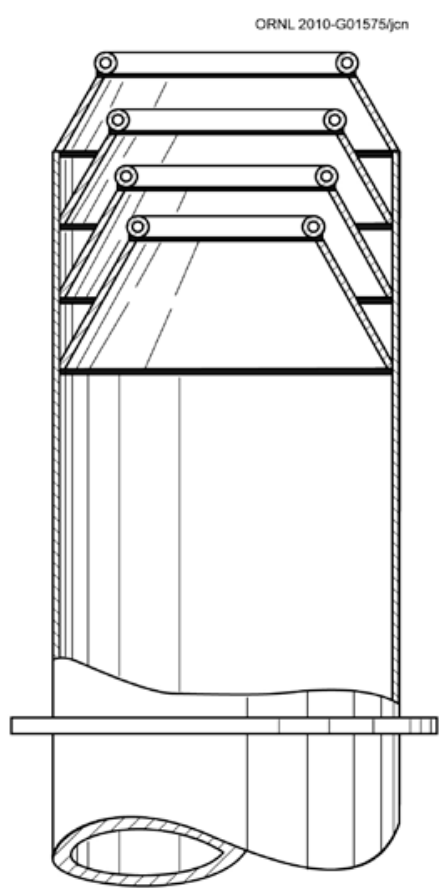

Fig. 2. Fluidic diode designed to prevent chimney backflow. (US Patent 4,092,908)

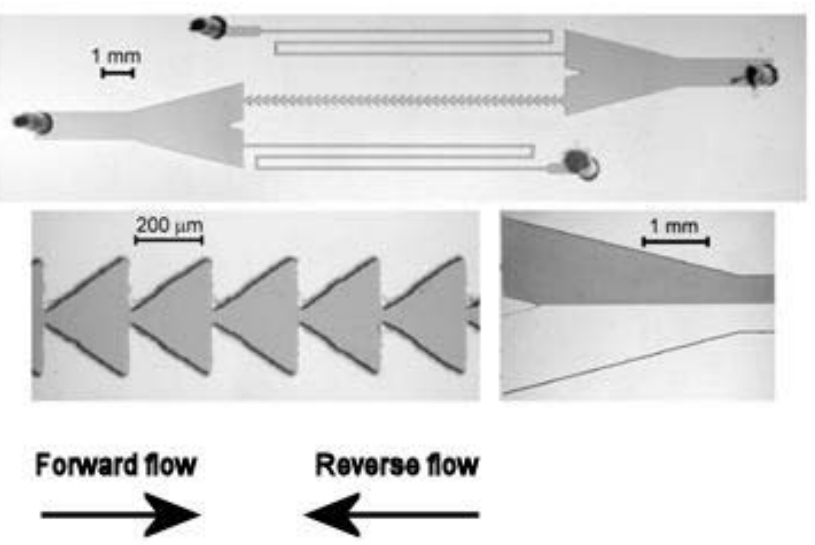

Fig. 3. Microchannel fluidic diode design. 

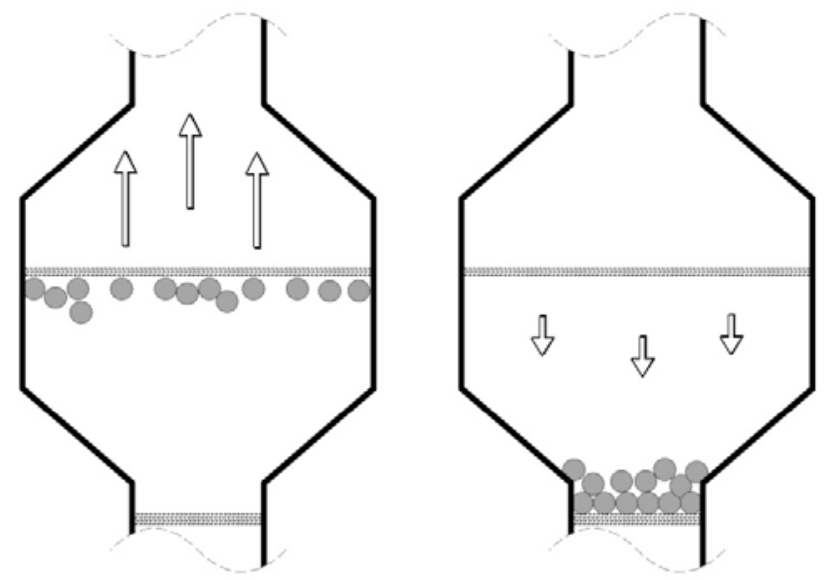

Fig. 4. Ball and screen fluidic diode design. Left figure shows the low-flow-resistance direction; right figure shows the high-flow-resistance direction. (US Patent 4,187,874)
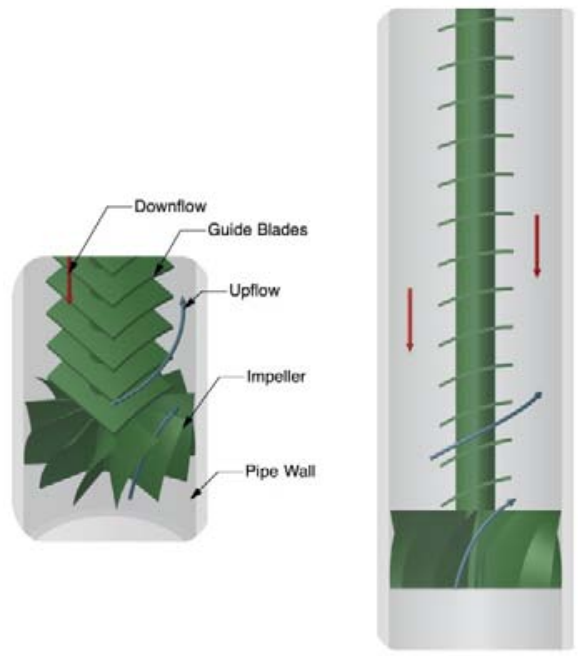

Fig. 5. Fluidic diode using swirl to increase flow resistance. As oriented, high resistance in the upward direction and low resistance in the downward direction.

Vortex diodes are presently used in the nuclear industry, mainly for radioactive waste pumping and transport. Two vortex diodes can be used to fashion a pumping system that has no moving parts. An example is shown in Fig. 7. In this pump design, gas pressure and vacuum are alternately applied to the tank.

Vortex diodes are attached to the tank in such a way that for one diode, flow out of the tank and through the diode is in the high-flow-resistance direction, and for the other flow diode, it is in the lowflow-resistance direction. When pressure is applied to the tank, flow wants to exit the tank through the flow diodes. More flow exits the diode that flows in the low-resistance direction (drive diode) and less through the one in the high-flow-resistance direction (refill diode). Similarly, if a vacuum is applied to the tank, flow wants to enter the tank through each diode. The flows through the diodes reverse, and now the high-flow-resistance direction is through the drive diode, and the low-flow-resistance direction is through the refill diode. A pump such as this has no moving parts and in general has all flow paths relatively open. A pump design of this type, although not very efficient, can be used to transport a variety of fluids, including those with entrained solids, and requires very little maintenance. 

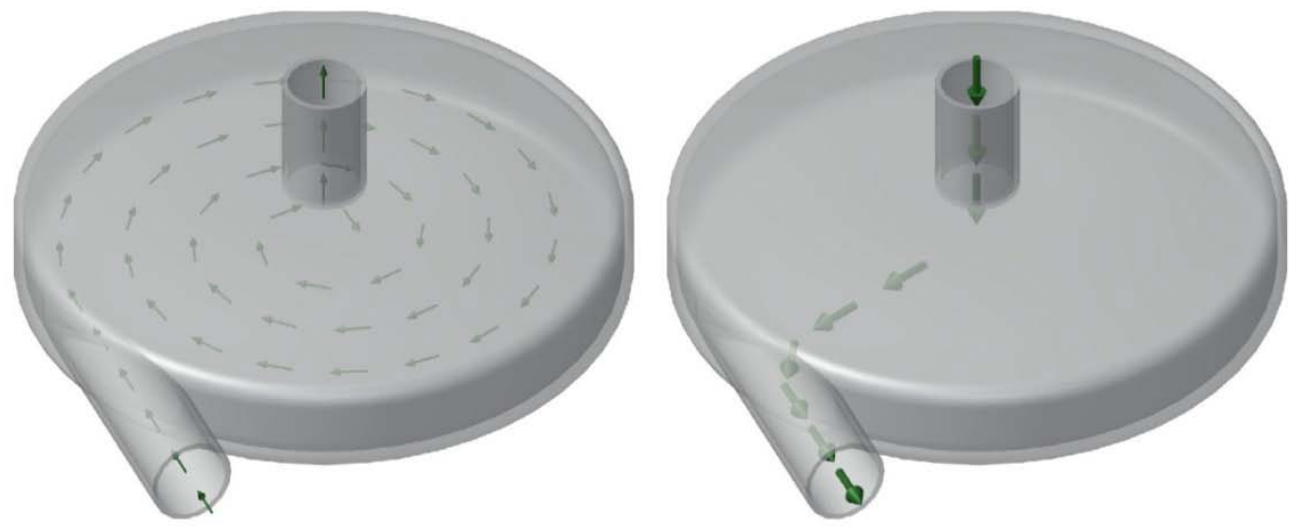

Fig. 6. Vortex diode.

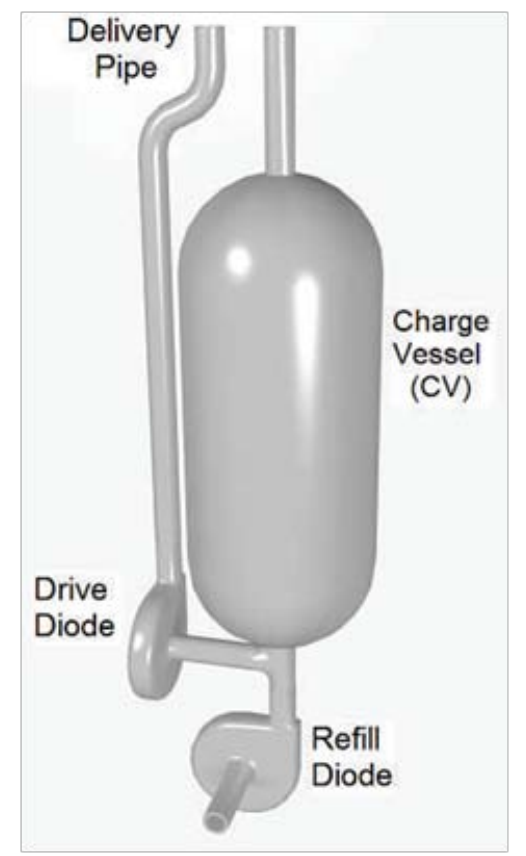

Fig. 7. Pumping system with no moving parts using vortex diodes (NuVision).

Several low-pressure, liquid-cooled reactor designs include a fluidic diode to control flow through heat exchange equipment used for passive reactor decay heat removal. The Pebble Bed Advanced High Temperature Reactor (PB-AHTR) is one of those reactor designs. ${ }^{3}$ A schematic of the 2008 version of this reactor design is presented in Fig. 8. During normal operation liquid salt coolant (FLiBe) is pumped into the reactor vessel (arrow pointing to the left at the right of the figure) and flows to the core that is composed of multiple beds of pebble fuel. The flow exits the core and then through the top of the vessel (arrow pointing right at the right of Fig. 8). Heat exchangers located outside of the reactor vessel are used to remove the heat generated by the core during normal operation. Piping parallel to the core creates a flow path to a direct reactor auxiliary cooling system (DRACS) that is used for decay heat cooling when there is no forced flow through the core. The DRACS is made up of a salt-to-salt heat exchanger (labeled DHX in the figure; the heat exchanger itself is indicated as a pink zigzag line, and the primary coolant salt 
in that system is indicated in blue) and a natural draft air-cooled heat exchanger (labeled passive decay heat removal in the figure). A second liquid salt loop connects these heat exchangers.

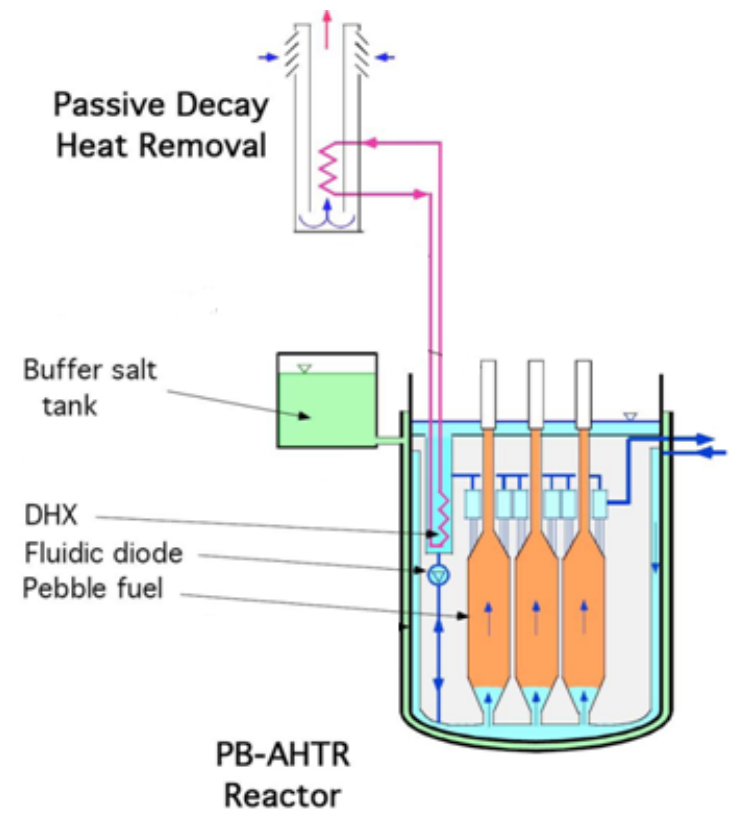

Fig. 8. The PB-AHTR reactor with the fluidic diode.

During normal operation the primary salt wants to flow upward through the secondary side of the DRACS salt-to-salt heat exchanger (DHX) from the bottom to the top of the core. Heat lost through the DRACS system during normal operation is a thermal loss in the overall system and therefore reduces operating efficiency. A fluidic diode included in this flow path at the bottom of the DHX is used to minimize this flow during normal operation and therefore minimize thermal losses. When the main circulation pumps are not operating, decay heat can be removed through the DRACS system. Once the pumps stop, as flow coasts down through the core, the DHX cools the primary salt in the DRACS, and the primary flow reverses from flowing upward in the DRACS system to downward (although flow is still upward in the core). The DRACS then removes decay heat through the secondary salt loop and discharges this heat to the atmosphere through the natural draft air cooler.

The ideal fluidic diode in a fluoride salt-cooled high-temperature reactor (FHR) should therefore offer minimum flow leakage during normal operation, while providing sufficient cooling during shutdown or emergency conditions through natural circulation. A vortex design has been chosen for the FHR because it has the most operating history and has the potential to give the desired flow characteristics.

We have performed initial parametric studies of vortex diodes to determine, first, the size that might be needed in the PB-AHTR and, second, the size of a similar diode that might be tested in the Oak Ridge National Laboratory (ORNL) Liquid Salt Flow Loop. The normal operating pressure drop through the core of the PB-AHTR is $440 \mathrm{kPa}$. The total core mass flow rate is about $3630 \mathrm{~kg} / \mathrm{s}$ and the coolant leakage around the fuel during normal operation is not to exceed $2.5 \%$ of the total mass flow rate. Multiple DRACS are used in the PB-AHTR design being studied. There are a total of eight independent DRACS, and there will be eight diodes connected to eight DHXs. (A single DRACS schematic is shown in Fig. 8.) 


\section{VORTEX DIODE DESIGN}

It is common design practice ${ }^{4,5}$ to make the inlet and exit ports of the vortex diode of equal diameters and to define the vortex diode's physical size by its disc diameter to its height ratio $\left(\mathrm{d}_{\mathrm{c}} / \mathrm{h}\right), \alpha$. The performance of the diode is characterized by the ratio of the pressure drop in the high-resistance flow direction to the pressure drop in the low-resistance flow direction for the same mass flow rate. This ratio is termed diodicity, $D$. Kulkarni et al.'s ${ }^{4}$ experimental results of vortex diodes show that the diodicity increases with $\alpha$ till it reaches approximately six, then it stays approximately constant with increasing $\alpha$. Similarly, Priestman ${ }^{6}$ and Tippetts and Priestman ${ }^{7}$ in their experimental studies of vortex diodes also found that diodicity approaches its maximum value when $\alpha$ is approximately six. Beyond this aspect ratio, diodicity will not increase as a result of an increase in the inlet mass flow rate. We therefore use an $\alpha$ equal to six for all of the diodes in this study. Kulkarni et al.' ${ }^{4}$ experimental study also showed that the diodicity increases with the Reynolds number until it reaches a certain value, at which it stays constant. They termed this Reynolds number the critical Reynolds number, $R e_{c}$. The Reynolds number, $R e$, was defined as

$$
\operatorname{Re}=\rho_{\mathrm{a}} \mathrm{V}_{\mathrm{a}} \mathrm{d}_{\mathrm{a}} / \mu
$$

where

$$
\begin{aligned}
& \rho_{a}=\text { density of fluid at the inlet port } \\
& V_{a}=\text { fluid velocity at the inlet port } \\
& d_{a}=\text { diameter of inlet port } \\
& \mu=\text { viscosity of fluid. }
\end{aligned}
$$

In this report we adopt the same nomenclature as that used by Kulkarni et al. ${ }^{4} \mathrm{~A}$ diagram of the vortex diode and the nomenclature used in this report is shown in Fig. 9.

To study the parametric behavior of vortex diodes and identify potential test diode configurations, we have developed computational fluid dynamics (CFD) models using the FLUENT CFD code ${ }^{8}$. These models have been used to simulate vortex diodes of various diameters, operating with different fluids, and operating over a range of Reynolds numbers.

Due to the complex three-dimensional nature of the flow inside vortex diodes, an analytical solution to the problem is impossible without significant simplifying assumptions. We therefore used the commercial CFD code FLUENT to perform a variety of parametric studies. The simulation of flow and turbulence in vortex diodes has been approached in different ways by different authors. For instance, Kulkarni et al. ${ }^{4}$ claimed that the turbulent flow inside the vortex chamber relaminarized and eliminated the need for any turbulent modeling. His experimental results showed good agreement with simulations using a laminar flow assumption when compared to simulations that used the standard k-epsilon (k- $\varepsilon$ ) turbulence model. Yang and Priestman ${ }^{9}$ claimed that the Reynolds stress turbulence model provided better agreement with their experimental results than the standard $k-\varepsilon$ turbulence model. Their reasoning was that the assumption of isotropic turbulence embedded in the $\mathrm{k}-\varepsilon$ model is not valid because of the geometry of the flow and that an anisotropic turbulence model was more appropriate. Yin et al. ${ }^{10}$ used a large eddy simulation (LES) technique and claimed an improved comparison because of the large pressure gradients that exist in vortex diodes that include unsteady pulsating flows. Yin justified using the LES method because the flow inside the vortex diode involves a large variety of eddy sizes and swirl number, $S$, (defined below) that varies from high to very small values in the vortex chamber. They noted that the renormalization group k- $\varepsilon$ turbulence model and the realizable k- $\varepsilon$ turbulence model are both suitable for low swirl numbers, and the Reynolds stress model is suitable for high swirl numbers. As a compromise they used an LES formulation. The LES model, however, requires a highly refined mesh (over 6,000,000 cells for some runs) and extensive computer time. 

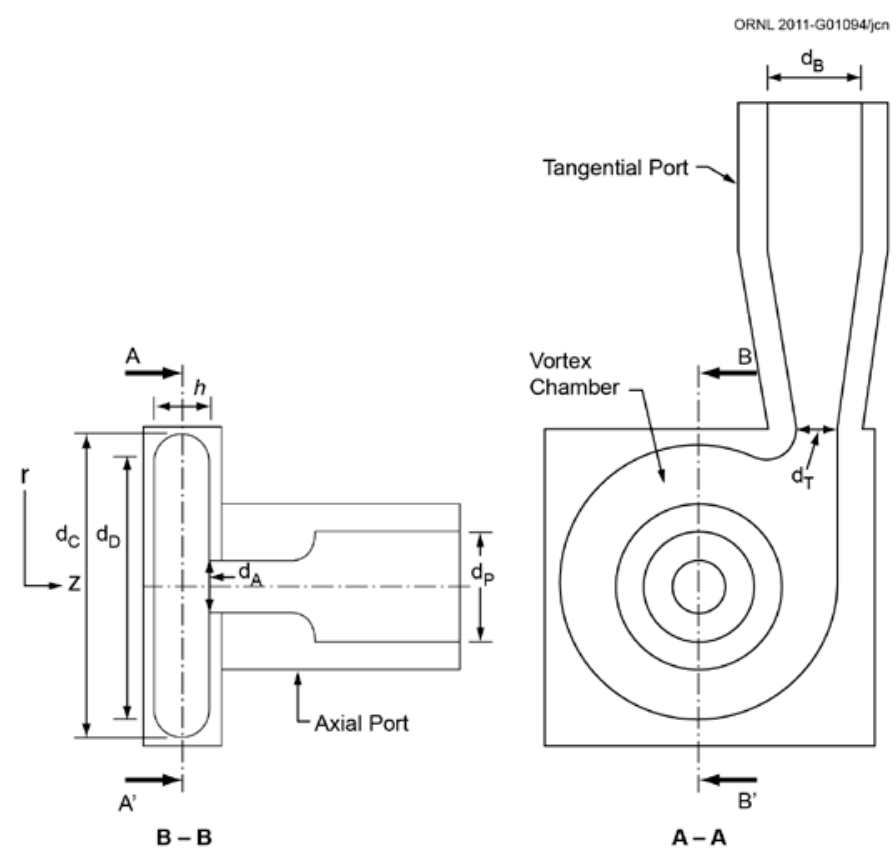

Fig. 9. Vortex diode dimension nomenclature.

\section{SIMULATION OF THE VORTEX DIODE}

The swirl number, $S$, is defined as

$$
S=\frac{\int_{0}^{R} U_{z} U_{\theta} r^{2} d r}{R \int_{0}^{R} U_{z}^{2} r d r}
$$

where

$$
\begin{aligned}
& \mathrm{Uz}=\text { velocity in the } \mathrm{z} \text { direction } \\
& \mathrm{U}_{\theta}=\text { velocity in the } \theta \text { direction } \\
& \mathrm{R}=\mathrm{d}_{\mathrm{c}} / 2 .
\end{aligned}
$$

The swirl number is therefore an indicator of the amount of rotation in the flow. In our case, $\theta$ is in the circumferential direction of the vortex chamber, $z$, is along the centerline of the axial port, and $R$ is the radius of the vortex chamber.

The performance of the diode is typically characterized by the diodicity. All experimental results and CFD simulations indicate that diodicity increases with the vortex chamber diameter up to a certain size and a certain mass flow rate. Other factors also affect diodicity, including the shape of the axial and tangential ports that connect the vortex chamber to the remainder of the fluid system. In the existing literature, a variety of tangential and axial port shapes have been examined including straight tubes, diffusers, and rectangular cross sections, as well as combinations of these. Priestman ${ }^{6}$ provided a detailed experimental study of vortex throttles and used different geometric shapes for the tangential and axial ports (circular and square sections) and sizes. The vast majority of previous research has focused more on the axial port shape than on the tangential one. For instance, Priestman ${ }^{6}$ studied five different designs for the axial port, whereas Kulkarni ${ }^{4}$ provided one shape but six different sizes. For all experiments diodicity varied with both shape and size of the ports. 
Another nondimensional number, the Euler number, $E u$, is used to characterize the pressure drop through the diode. Euler number is defined as

$$
\mathrm{Eu}=\frac{\Delta P}{\rho \mathrm{V}^{2}},
$$

where

$$
\begin{aligned}
& \Delta \mathrm{P}=\text { pressure drop } \\
& \rho=\text { fluid density } \\
& \mathrm{V}=\text { fluid velocity. }
\end{aligned}
$$

The effect of the port sizes on the Euler number is not clearly understood as shown by Kulkarni et al.'s ${ }^{4}$ experimental results. Port size and shape will have an impact on vortex performance because inlet velocity patterns and pressure distribution have an effect on the pressure drop and the flow structure within the diode chamber. The experimental data of Kulkarni et al. ${ }^{4}$ and Priestman ${ }^{6}$ indicate that an increase in vortex diode size and mass flow rate will increase diodicity up to a certain diode size (that was $\sim 100 \mathrm{~mm}$ for Kulkarni et al. ${ }^{4}$ ) and mass flow rate (or Reynolds number). Beyond that diameter and mass flow rate, diodicity remained relatively constant. The shape and sizes of connecting ports to the diode chamber will affect diodicity but in a way not fully described by existing literature.

For our CFD calculations, the vortex diode was simulated with a circular disc-shaped vortex chamber fitted with tangential and axial ports of circular cross section. Both tangential and axial port diameters were assumed to be equal to the height of the circular discs. The solid model (Fig. 10) was meshed using the $\mathrm{GAMBIT}^{11}$ mesher.

In most cases the number of cells used was between 1,250,000 and 1,500,000, and most cases were run with tetrahedron-shaped cells internal to the mesh and triangular cells on the faces. The skewness of the mesh was less than 0.8 for all cases studied. Convergence was achieved when two conditions were attained: (1) when the residuals for the continuity, momentum, and velocities reached a set criterion (usually $10^{-6}$ ) and (2) when the mass flow rate or pressure drop values stayed constant. For reverse flow we used a pressure-based solver and a coupled velocity and pressure solution, with inlet and outlet ports as pressure outlets. For forward flow we used a pressure-based solver and a coupled velocity and pressure solution specifying the mass flow rate at the inlet port and a fixed pressure at the exit port. For most cases we used a $\mathrm{k}-\varepsilon$ two-equation turbulence model. (Where this was not the case, the model used is specified in the tabulated results.)

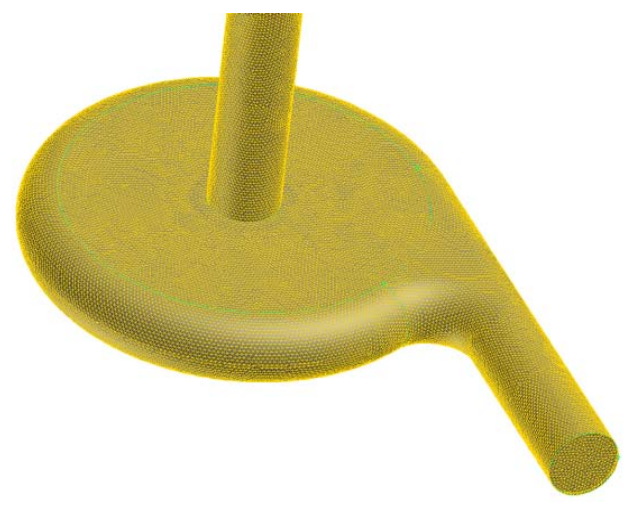

Fig. 10. Typical vortex diode configuration meshed with GAMBIT. 


\section{CALCULATION RESULTS}

Parametric simulations were performed for diode sizes ranging from 152 to $635 \mathrm{~mm}$ in diameter and for different fluids and different Reynolds numbers. Table 1 below shows a summary of these results using $700^{\circ} \mathrm{C}$ FLiBe as the fluid. These cases were run to determine approximate sizes that might be used in the PB-AHTR reactor design. The pressure drop in the reverse flow direction was assumed to be the core pressure drop of the PB-AHTR, and a CFD analysis was run to determine the reverse mass flow through the diode. This mass flow was then used to run a second calculation in the forward flow direction to determine the pressure drop in the forward flow direction and therefore the diodicity. As indicated in the table, the larger the diode, the higher the diodicity up to a certain diode size, then diodicity becomes independent of diode size. All runs show the effect of the Reynolds number on the diodicity. As indicated, the diodicity tends to increase with increased Reynolds numbers (or mass flow rates). This conclusion is consistent with conclusions reached by other investigators (references. 4 and 5, for instance). Figure 11 shows the results of all of the FLiBe calculations. The expected increase in diodicity with Reynolds number is clearly seen when plotted in this manner. Additionally, this figure shows significant differences in predicted diodicity when using the $\mathrm{k}-\varepsilon$ model when default values for length scale and intensity are selected versus the modified ones, which are believed to better characterize the flow within the diode. We have selected modified intensity and length-scale values for the k- $\varepsilon$ model. Using reference 8, length scales are assumed to be $7 \%$ of the diode inlet diameter, and the intensity is calculated using the following formula:

$$
\mathrm{I}=16^{*} \mathrm{Re}^{-1 / 8}
$$

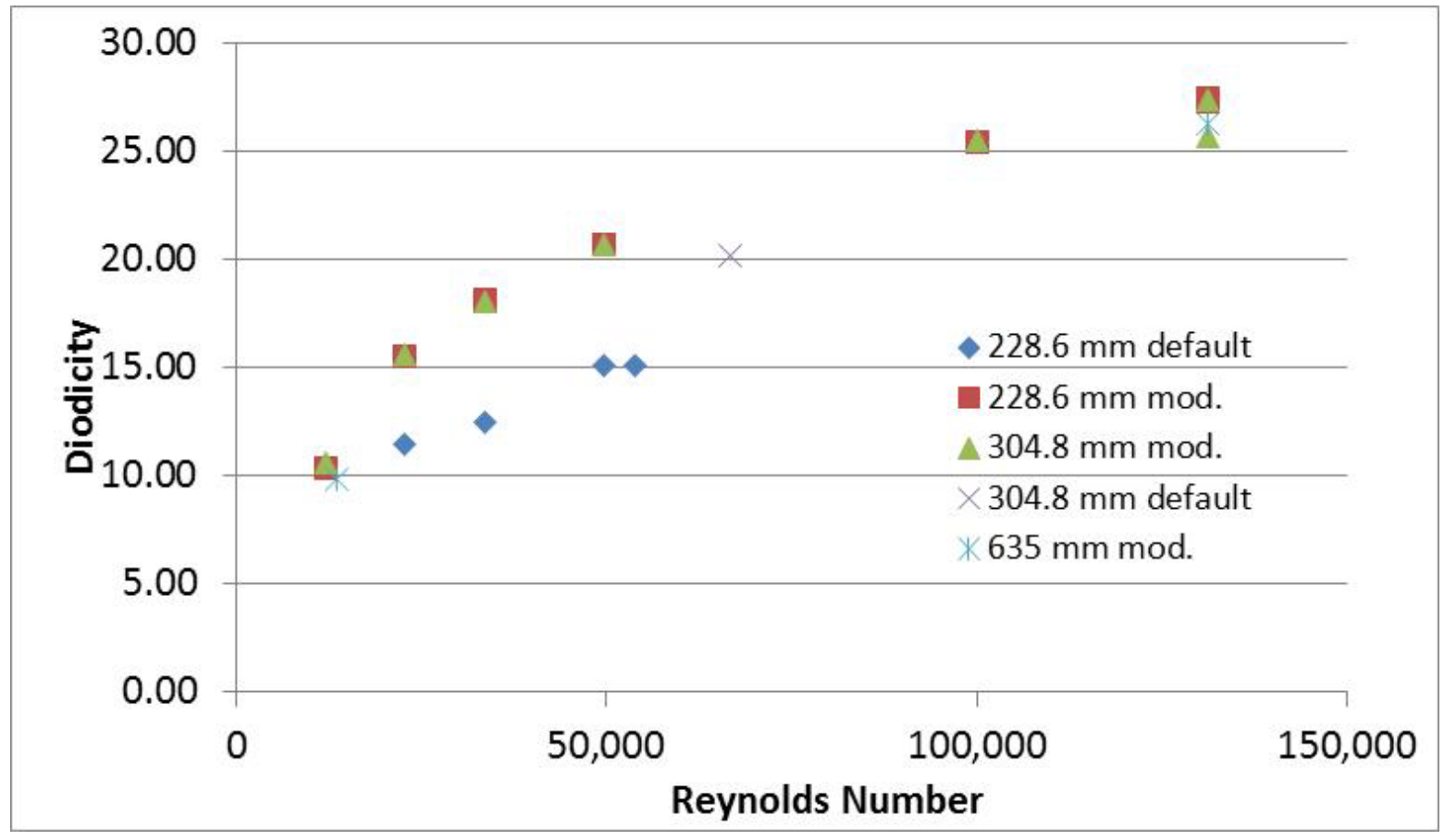

Fig. 11. Diodicity for all FLiBe calculations. 
Table 1. Results of FLUENT analysis for three diode designs using FLiBe as the fluid

\begin{tabular}{|c|c|c|c|c|c|c|c|c|c|c|}
\hline $\begin{array}{l}\text { Diode } \\
\text { diam. } \\
(\mathrm{mm})\end{array}$ & $\begin{array}{l}\text { Reynolds } \\
\text { number }\end{array}$ & Diodicity & $\mathbf{D P}_{\mathbf{f}}(\mathbf{P a})$ & $\mathbf{D P}_{\mathrm{r}}(\mathbf{P a})$ & $\begin{array}{c}\text { Inlet } \\
\text { diam. } \\
(\mathbf{m})\end{array}$ & $\mathbf{E} \mathbf{u}_{\mathbf{f}}$ & $\mathbf{E} \mathbf{u}_{\mathbf{r}}$ & $\begin{array}{l}\text { Length } \\
\text { scale (m) }\end{array}$ & Intensity \% & $\begin{array}{c}\text { Turbulence } \\
\text { model }\end{array}$ \\
\hline 228.6 & 53,818 & 15.06 & 28,171 & 424,384 & 0.03810 & 0.903999641 & 13.61836582 & 1 & 10 & k- $\varepsilon$ realizable (default settings) \\
\hline 228.6 & 22,773 & 11.44 & 5,491 & 62,812 & 0.03810 & 0.984080968 & 11.25698302 & 1 & 10 & k- $\varepsilon$ realizable (default settings) \\
\hline 228.6 & 33,490 & 12.46 & 12,112 & 150,897 & 0.03810 & 1.003714727 & 12.50475076 & 1 & 10 & k- $\varepsilon$ realizable (default settings) \\
\hline 228.6 & 49,565 & 15.06 & 28,172 & 424,384 & 0.03810 & 1.065840183 & 16.05585405 & 1 & 10 & k- $\varepsilon$ realizable (default settings) \\
\hline 228.6 & 12,000 & 10.38 & 1,256 & 13,037 & 0.03810 & 0.81064868 & 8.414352579 & 0.002667 & 4.945638026 & $\mathrm{k}-\varepsilon$ realizable \\
\hline 228.6 & 100,000 & 25.44 & 69,497 & $1,768,208$ & 0.03810 & 0.645909378 & 16.43383354 & 0.002667 & 3.794197929 & $\mathrm{k}-\varepsilon$ realizable \\
\hline 228.6 & 131,205 & 27.45 & 117,499 & $3,225,476$ & 0.03810 & 0.634364588 & 17.41400144 & 0.002667 & 3.667551192 & k- $\varepsilon$ realizable \\
\hline 228.6 & 12,000 & 10.38 & 1,256 & 13,037 & 0.0381 & 0.81064868 & 8.414352579 & 0.002667 & 4.945638026 & k- $\varepsilon$ realizable \\
\hline 228.6 & 22,773 & 15.54 & 3,951 & 61,408 & 0.0381 & 0.708060788 & 11.00495998 & 0.002667 & 4.565016552 & $\mathrm{k}-\varepsilon$ realizable \\
\hline 228.6 & 33,490 & 18.13 & 8,214 & 148,885 & 0.0381 & 0.680669296 & 12.3376489 & 0.002667 & 4.350167488 & k- $\varepsilon$ realizable \\
\hline 228.6 & 49,565 & 20.66 & 17,612 & 363,899 & 0.0381 & 0.666295365 & 13.76698938 & 0.002667 & 4.142125651 & k- $\varepsilon$ realizable \\
\hline 228.6 & 100,000 & 25.44 & 69,497 & $1,768,208$ & 0.0381 & 0.645909378 & 16.43383354 & 0.002667 & 3.794197929 & k- $\varepsilon$ realizable \\
\hline 228.6 & 131,205 & 27.45 & 117,499 & $3,225,477$ & 0.0381 & 0.634364588 & 17.41400684 & 0.002667 & 3.667551192 & k- $\varepsilon$ realizable \\
\hline 228.6 & 22,773 & 15.53 & 3,951 & 61,369 & 0.0381 & 0.708124408 & 10.99797246 & 0.002667 & 4.565017554 & k- $\varepsilon$ realizable \\
\hline 228.6 & 33,490 & 18.06 & 8,239 & 148,796 & 0.0381 & 0.682763468 & 12.33029769 & 0.002667 & 4.350163591 & k- $\varepsilon$ realizable \\
\hline 228.6 & 49,565 & 20.66 & 17,612 & 363,901 & 0.0381 & 0.666297067 & 13.76704715 & 0.002667 & 4.14212398 & k- $\varepsilon$ realizable \\
\hline 228.6 & 100,000 & 25.44 & 69,497 & $1,768,205$ & 0.0381 & 0.645908579 & 16.43380177 & 0.002667 & 3.794197929 & k- $\varepsilon$ realizable \\
\hline 228.6 & 131,205 & 27.33 & 118,466 & $3,237,554$ & 0.0381 & 0.63958791 & 17.47921038 & 0.002667 & 3.667551192 & k- $\varepsilon$ realizable \\
\hline 304.8 & 12,000 & 10.64 & 699 & 7,434 & 0.0508 & 0.801662091 & 8.529511161 & 0.003556 & 4.945638026 & k- $\varepsilon$ realizable \\
\hline 304.8 & 22,773 & 15.57 & 2,225 & 34,646 & 0.0508 & 0.708732868 & 11.03824822 & 0.003556 & 4.565017554 & k- $\varepsilon$ realizable \\
\hline 304.8 & 33,490 & 18.09 & 4,639 & 83,896 & 0.0508 & 0.683364925 & 12.35953042 & 0.003556 & 4.350163591 & k- $\varepsilon$ realizable \\
\hline 304.8 & 49,565 & 20.68 & 9,914 & 205,033 & 0.0508 & 0.666776519 & 13.78981782 & 0.003556 & 4.14212398 & k- $\varepsilon$ realizable \\
\hline 304.8 & 100,000 & 25.49 & 39,104 & 996,812 & 0.0508 & 0.646103645 & 16.47010417 & 0.003556 & 3.794197929 & k- $\varepsilon$ realizable \\
\hline 304.8 & 131,205 & 27.36 & 66,692 & $1,824,708$ & 0.0508 & 0.640113364 & 17.51360359 & 0.003556 & 3.667551192 & k- $\varepsilon$ realizable \\
\hline 304.8 & 131,205 & 25.72 & 66,444 & $1,709,000$ & 0.05080 & 0.637731698 & 16.40303824 & 0.003556 & 3.667551192 & $\mathrm{k}-\varepsilon$ realizable \\
\hline 304.8 & 66,650 & 20.17 & 21,147 & 426,525 & 0.05080 & 0.786587163 & 15.86513291 & 1 & 10 & k- $\varepsilon$ realizable (default settings) \\
\hline 635 & 13,667 & 9.81 & 237 & 2,325 & 0.10583 & 0.909918486 & 8.926415523 & 1 & 10 & k- $\varepsilon$ realizable (default settings) \\
\hline 635 & 131,205 & 26.29 & 16,275 & 427,860 & 0.10583 & 0.677986048 & 17.82384704 & 1 & 10 & k- $\varepsilon$ realizable (default settings) \\
\hline
\end{tabular}


CFD calculations have also been performed to examine other liquid salts. Table 2 shows results of calculations using FLiNaK salt at $700^{\circ} \mathrm{C}$. FLiNaK is the salt that will be used in the Liquid Salt Flow Loop diode tests. It is expected that flows through these devices will be turbulent. However, because it has been suggested in the literature that the vortex has the potential to relaminarize the flow once it enters the dioide, a comparison was made between assuming laminar and turbulent flow in the diode. To do this, one diode size was examined. FLUENT calculations were first run using the k- $\varepsilon$ turbulence model and then run again assuming laminar flow. Results of these calculations are shown in row 2 (turbulent) and row 1 (laminar) in Table 2. As before, a $440 \mathrm{kPa}$ pressure drop across the diode in reverse flow was assumed. As Table 2 indicates, and as expected, flow for the laminar assumption was higher than that for the turbulent one. The flow rates were about $25 \%$ different, and the calculated diodicities were different by about $23 \%$. The conclusion is that if relaminarization should actually occur in the diode and it was designed using turbulent assumptions, the flow rate through the diode would be greater than expected, and the diodicity would be smaller than expected.

A 228.6 mm diode case was run for both FLiNaK (row 12, Table 2) and FLiBe (row 4, Table 1) to compare the behavior of different fluids. Again, $\sim 440 \mathrm{kPa}$ was assumed for the reverse flow pressure drop. FLiNaK viscosity is about one-half that of FLiBe, and the densities are about the same. Because the reverse flow pressure drop is dominated by momentum forces rather than viscous, the reverse flow rates through the diode are almost equal. However, in the forward flow direction in which viscous forces are more important, the pressure drop through the FLiNaK diode is less than that of the FLiBe diode. The Reynolds number is significantly higher for FLiNaK because of the viscosity differences, and the diodicity is significantly higher for the FLiNaK case, which is consistent with other references.

A specific case was run to size a diode that might be tested in the ORNL liquid salt flow loop. The maximum pump head in this loop is $0.125 \mathrm{MPa}$, and the maximum flow rate is $4.5 \mathrm{~kg} / \mathrm{s}$. FLUENT calculations were run for a $152.4 \mathrm{~mm}$ diode operating with FLiNaK, and the results are shown in Table 2 (row 15). Calculations were first run to determine the flow rate in reverse flow at the maximum pressure output of the pump. The diode was calculated to require a reverse flow rate of $2.264 \mathrm{~kg} / \mathrm{s}$ at this pressure drop. This is under the maximum loop pump output of $4.5 \mathrm{~kg} / \mathrm{s}$, so it should be possible to test this diode in the loop under reverse flow conditions. In the forward flow direction for the same flow rate, a pressure drop of 8,100 Pa was calculated. This pressure drop should be measurable using available hightemperature pressure transducer designs. Therefore, it should be possible to test a $152.4 \mathrm{~mm}$ diode in the liquid salt loop system with some modifications.

Additional design details were added to the $152.4 \mathrm{~mm}$ diode in an attempt to improve the diode's performance. It was noted that a significant amount of swirl still existed in reverse flow in the axial port under reverse flow conditions. To eliminate that swirl component, straightening veins were added in the axial port. Additionally, various authors have suggested that a rounded expansion in the axial port (in reverse flow) would also increase diodicity. These two features were added to the $152.4 \mathrm{~mm}$ diode above, and it was enlarged to compensate for the pressure drop added by the veins and expansion, making the modified diode $171.4 \mathrm{~mm}$ in diameter. The resulting diode design is shown in Fig. 12.

The design includes reinforcing structures external to the diode that allow higher internal diode pressures. Ribs integral to the diode and a pair of plates used to "sandwich" the diode are incorporated in this design. This diode design was also analyzed using the FLUENT code. Results are reported in Table 2 (rows 13 and 14, indicated as a $171.45 \mathrm{~mm}$ diode) for two turbulence models .As indicated in the table, the diodicity is dependent on the turbulence model chosen and is actually less than that of an equivalent diode without the enhancements. The enhanced diode design has been tested using water, and experimental results are discussed in Chapter 6. Additional calculations will be needed to finalize the diode design to be tested in salt.

Several calculations were also performed using water as the fluid for a single diode size of $114.3 \mathrm{~mm}$. Results are presented in Table 3. As with the FLiNaK calculations, both laminar and turbulent cases were run, and the results are very similar; calculated diodicity is significantly higher when turbulence is assumed. 
Table 2. Results of FLUENT analysis for four different diode designs using FLiNaK as the fluid

\begin{tabular}{|c|c|c|c|c|c|c|c|c|c|c|}
\hline $\begin{array}{l}\text { Diode } \\
\text { diam. } \\
\text { (mm) }\end{array}$ & $\begin{array}{l}\text { Reynolds } \\
\text { number }\end{array}$ & Diodicity & $\mathbf{D P}_{\mathrm{f}}(\mathbf{P a})$ & $\mathbf{D P} P_{\mathrm{r}}(\mathbf{P a})$ & $\begin{array}{l}\text { Inlet } \\
\text { diam. } \\
\text { (m) }\end{array}$ & $\mathbf{E} \mathbf{u}_{\mathrm{f}}$ & $\mathbf{E} \mathbf{u}_{\mathrm{r}}$ & $\begin{array}{c}\text { Length } \\
\text { scale } \\
\text { (m) } \\
\end{array}$ & $\begin{array}{c}\text { Intensity } \\
\%\end{array}$ & $\begin{array}{l}\text { Turbulence } \\
\text { model }\end{array}$ \\
\hline 381 & 178005.8 & 22.93155 & 18510 & 424463 & 0.0635 & 0.5631 & 12.9125 & $\mathrm{n} / \mathrm{a}$ & $\mathrm{n} / \mathrm{a}$ & Laminar \\
\hline 381 & 140748.7 & 29.95622 & 14343 & 429662 & 0.0635 & 0.6979 & 20.9063 & 1 & 10 & k- $\varepsilon$ realizable (default settings) \\
\hline 381 & 43063 & 19.72755 & 1292 & 25488 & 0.0635 & 0.6716 & 13.2485 & 0.0044 & 4.2156 & 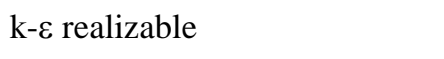 \\
\hline 381 & 75000 & 23.47151 & 3809 & 89403 & 0.0635 & 0.6527 & 15.3204 & 0.0044 & 3.9331 & $\mathrm{k}-\varepsilon$ realizable \\
\hline 381 & 150000 & 28.2784 & 14859 & 420188.7 & 0.0635 & 0.6366 & 18.0012 & 0.0044 & 3.6067 & $\mathrm{k}-\varepsilon$ realizable \\
\hline 228.6 & 28709 & 17.046 & 1643.3 & 28011.7 & 0.0381 & 0.6919 & 11.7936 & 0.0027 & 4.4347 & $k-\varepsilon$ realizable \\
\hline 228.6 & 33490 & 18.04624 & 2206 & 39810 & 0.0381 & 0.6825 & 12.3170 & 0.0027 & 4.3502 & 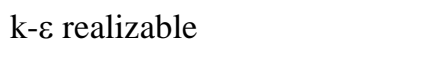 \\
\hline 228.6 & 49565 & 20.66179 & 4716 & 97441 & 0.0381 & 0.6661 & 13.7637 & 0.0027 & 4.1421 & k-є realizable \\
\hline 228.6 & 100000 & 25.44187 & 18612 & 473524 & 0.0381 & 0.6459 & 16.4318 & 0.0027 & 3.7942 & 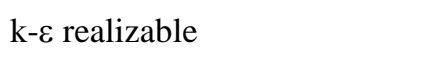 \\
\hline 228.6 & 131205 & 27.32987 & 31729 & 867149.6 & 0.0381 & 0.6396 & 17.4798 & 0.0027 & 3.6676 & $\mathrm{k}-\varepsilon$ realizable \\
\hline 228.6 & 43063 & 19.71301 & 3589 & 70750 & 0.0381 & 0.6716 & 13.2391 & 0.0027 & 4.2156 & 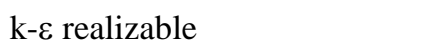 \\
\hline 228.6 & 97167.22 & 17.78011 & 23967 & 426136 & 0.0381 & 0.8809 & 15.6621 & \multicolumn{2}{|c|}{110} & k- $\varepsilon$ realizable (default settings) \\
\hline 171.45 & 41051.71 & 9.461305 & 13180 & 124700 & 0.0266 & 1.327 & 12.5578 & 0.0019 & 4.2409 & k- $\varepsilon$ standard \\
\hline 171.45 & 41026.55 & 8.702304 & 13413 & 116724 & 0.0266 & 1.3506 & 11.7535 & 0.0037 & 4.6159 & k-є realizable \\
\hline 152.4 & 39050.87 & 14.80634 & 8107 & 120035 & 0.0254 & 0.8199 & 12.1396 & 1 & 10 & k- $\varepsilon$ realizable (default settings) \\
\hline 152.4 & 43063.25 & 19.71625 & 8074 & 159189 & 0.0254 & 0.671483 & 13.2391198 & 0.001778 & 4.215573 & 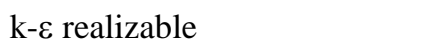 \\
\hline
\end{tabular}

Table 3. Results of FLUENT analysis for a single diode design using water as the fluid

\begin{tabular}{|c|c|c|c|c|c|c|c|c|c|c|}
\hline $\begin{array}{l}\text { Diode } \\
\text { diam. } \\
(\mathrm{mm})\end{array}$ & $\begin{array}{l}\text { Reynolds } \\
\text { number }\end{array}$ & Diodicity & $\mathbf{D P}_{\mathrm{f}}(\mathbf{P a})$ & $\mathrm{DP}_{\mathrm{r}}(\mathrm{Pa})$ & $\begin{array}{c}\text { Inlet } \\
\text { diam. } \\
(\mathbf{m})\end{array}$ & $\mathbf{E u}_{\mathbf{f}}$ & $\mathbf{E} \mathbf{u}_{\mathbf{r}}$ & $\begin{array}{c}\text { Length } \\
\text { scale } \\
\text { (m) } \\
\end{array}$ & $\begin{array}{c}\text { Intensity } \\
\%\end{array}$ & $\begin{array}{c}\text { Turbulence } \\
\text { model }\end{array}$ \\
\hline 114.3 & 17,785 & 11.43 & 811 & 9,267 & 0.01905 & 0.9230 & 10.5471 & $\mathrm{n} / \mathrm{a}$ & $\mathrm{n} / \mathrm{a}$ & Laminar \\
\hline 114.3 & 12,886 & 7.06 & 538 & 3,797 & 0.01905 & 1.1665 & 8.2329 & $\mathrm{n} / \mathrm{a}$ & $\mathrm{n} / \mathrm{a}$ & Laminar \\
\hline 114.3 & 12,500 & 11.06 & 337 & 3,727 & 0.01905 & 0.7765 & 8.5873 & 0.0013 & 4.9205 & k- $\varepsilon$ realizable \\
\hline 114.3 & 20,000 & 14.31 & 809 & 11,580 & 0.01905 & 0.7281 & 10.4224 & 0.0013 & 4.6397 & k- $\varepsilon$ realizable \\
\hline 114.3 & 12,500 & 10.74 & 348 & 3,738 & 0.01905 & 0.8018 & 8.6127 & 0.0013 & 4.9205 & k- $\varepsilon$ realizable \\
\hline
\end{tabular}



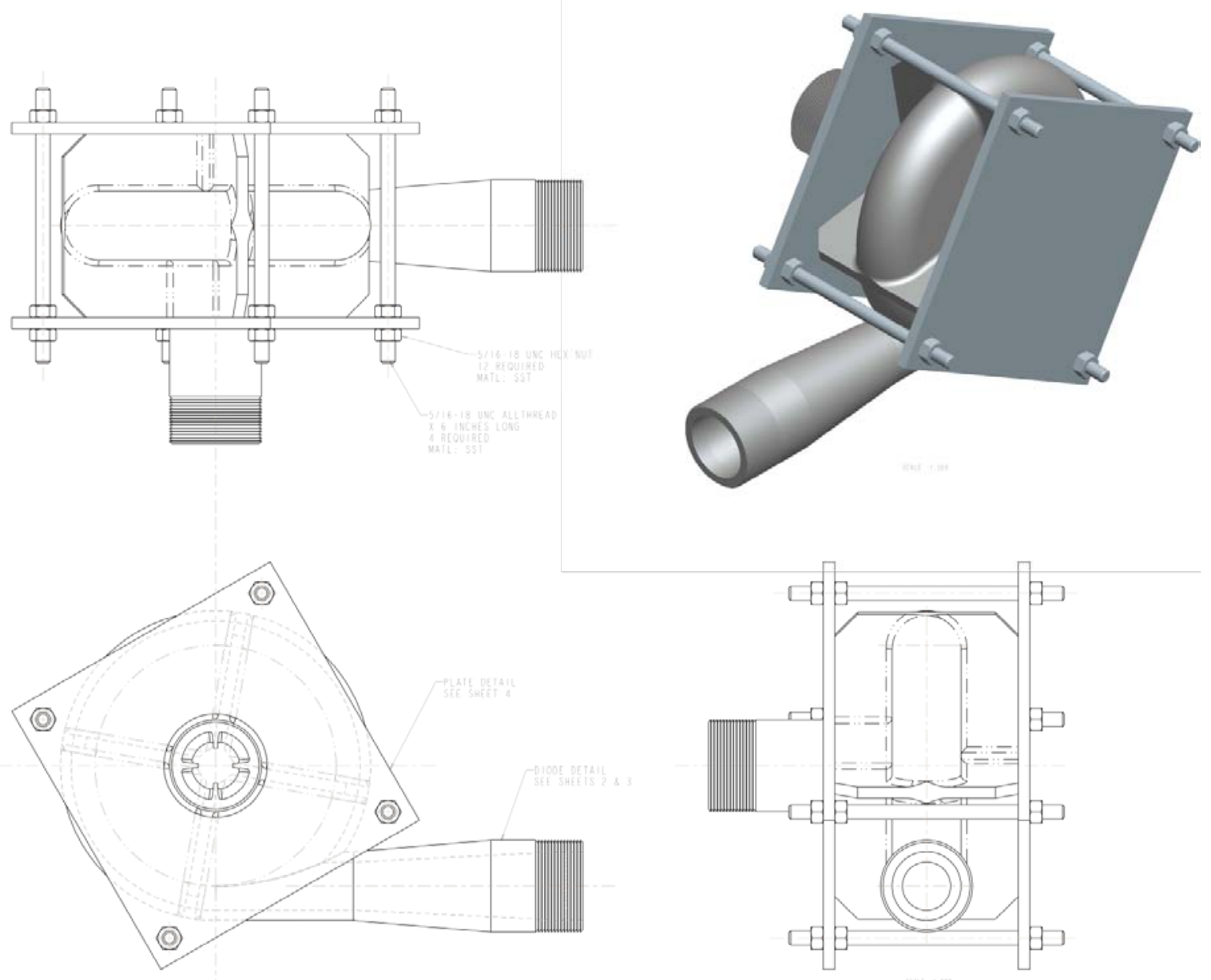

Fig. 12. Drawing of $\mathbf{1 7 1 . 4} \mathbf{~ m m}$ diode with enhanced design features.

There are many factors that affect the CFD solutions. These include the mesh size, flow structure classification (turbulent or laminar flow), and turbulent model used for analysis. A mesh size study was performed to evaluate the impact of mesh size on calculation results. Results of this study are shown in Table 4 below. Three runs were made to check the effect of the number of cells on the diodicity of the vortex diode. It is shown that the $1500 \mathrm{~K}$ mesh size produced about $17 \%$ higher predicted diodicity than models using a smaller cell count. We are planning more runs to investigate the effect of higher mesh size-up to 3M size. All diode calculations in this report used $\sim 1500 \mathrm{~K}$ cells.

Table 4. Effect of mesh size (number of cells)

\begin{tabular}{ccccccccc}
\hline $\begin{array}{c}\text { Total } \\
\text { number } \\
\text { of cells }\end{array}$ & $\begin{array}{c}\text { Diode diam. } \\
\mathbf{( m m )}\end{array}$ & $\begin{array}{c}\text { Reynolds } \\
\text { number }\end{array}$ & Diodicity & $\mathbf{E u}_{\mathbf{f}}$ & $\mathbf{E u}_{\mathbf{r}}$ & $\begin{array}{c}\text { Length } \\
\text { scale } \\
(\mathbf{m})\end{array}$ & $\begin{array}{c}\text { Intensity } \\
\mathbf{\%}\end{array}$ & Fluid \\
\hline $650 \mathrm{~K}$ & 228.6 & 49,565 & 19.74 & 0.6681 & 13.1894 & 0.0027 & 4.1421 & FLiNaK \\
$750 \mathrm{~K}$ & 228.6 & 49,565 & 20.66 & 0.6661 & 13.7637 & 0.0027 & 4.1421 & FLiNaK \\
$1500 \mathrm{~K}$ & 228.6 & 49,565 & 23.93 & 0.6695 & 16.0188 & 0.0027 & 4.1421 & FLiNaK \\
\hline
\end{tabular}


Figure 13 shows the CFD results for diodicity versus the Reynolds number for only the $228.6 \mathrm{~mm}$ and $304.8 \mathrm{~mm}$ diodes. Most of the calculations were run assuming a $440 \mathrm{kPa}$ pressure drop in the reverse flow direction. The Reynolds number increased because of a size increase in the diode. (Both mass flow through the diode and characteristic dimension increased.) It has been shown in experimental studies (see Ref. 5) that diodicity should increase smoothly with Reynolds number for a given diode size. As shown in Fig. 13, this was the case for the $228.6 \mathrm{~mm}$ and $304.8 \mathrm{~mm}$ diodes analyzed in this study. These results also show that diodicity was independent of diode sizes. The same trend is observed in Kulkarni's ${ }^{5}$ watertesting results for diode sizes comparable to ours. The results of those tests showed diodicities up to 50 for this diode and Reynolds numbers above about 25,000. In the CFD cases presented here, the largest diodicity we have calculated is approximately 30 for significantly larger diodes (380 m). The explanation for the discrepancy is not clear at this point, and additional investigation is needed to determine the reasons for the differences.

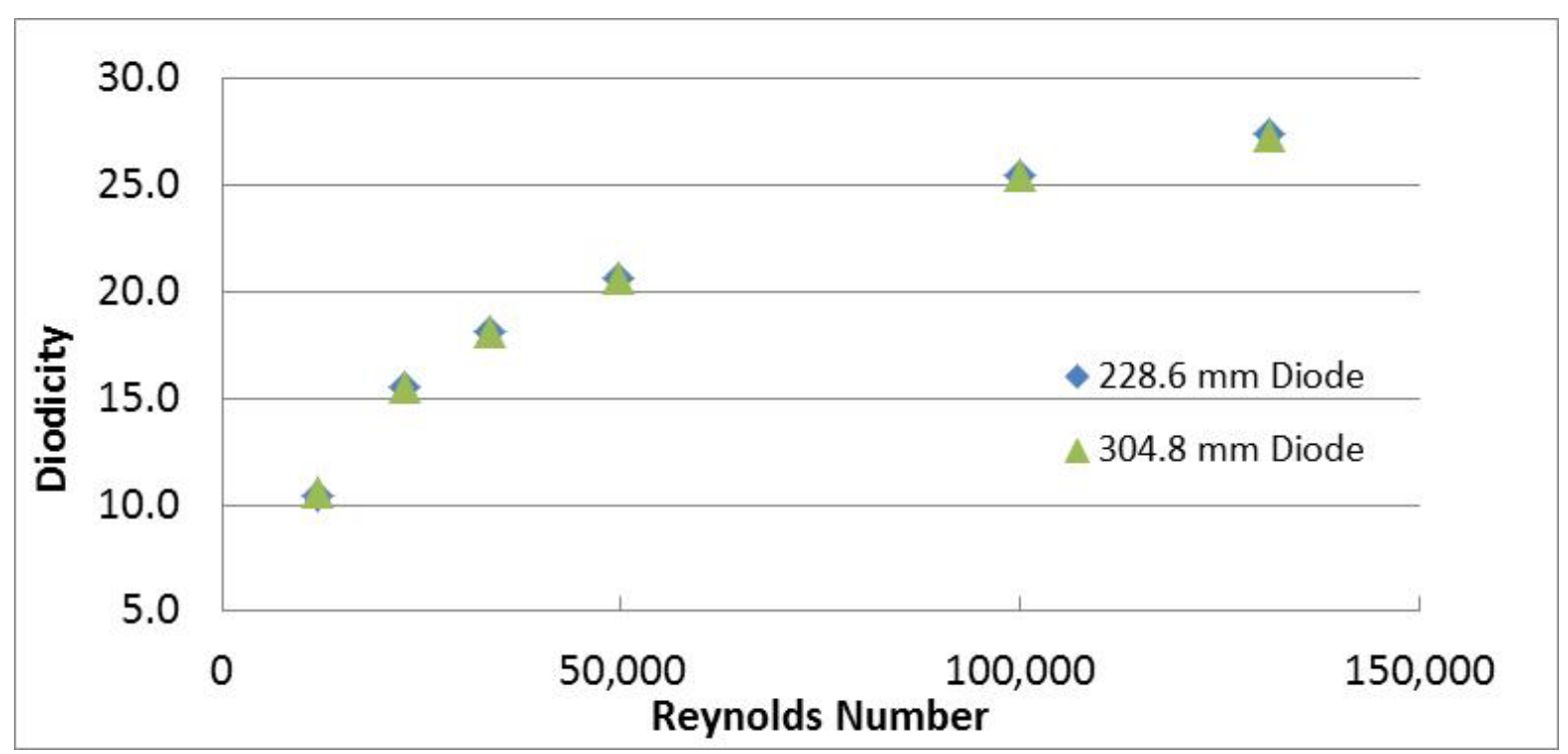

Fig. 13. Diodicity versus Reynolds number for $228.6 \mathrm{~mm}$ and $304.8 \mathrm{~mm}$ diodes.

Figures 14 and 15 show results for Euler number versus Reynolds number for $228.6 \mathrm{~mm}$ and $304.8 \mathrm{~mm}$ diodes. The trend with Reynolds number is clear and is consistent with other investigations. Euler number increases with Reynolds number for the reverse direction and decreases in the forward direction.

Data from all of the CFD runs are presented in Fig. 16. These results show that, at least for the diode sizes analyzed here, the diodicity for all of the fluids and all diodes can reasonably be described as a function of Reynolds number. The results in this figure represent only those data that were developed using the realizible $\mathrm{k}-\varepsilon$ turbulence model with modified length-scale and intensity values.

Figures 17 and 18 show path lines for a $304.8 \mathrm{~mm}$ FLiBe diode operating at $430 \mathrm{kPa}$ in both the reverse (Fig. 17) and forward (Fig.18) directions. Figure 17 shows a reasonably uniform flow pattern in the reverse direction. However, there still exists some swirl flow in the outlet, implying that the overall effect of the diode on reverse flow pressure drop might be slightly underestimated in these calculations. Figure 18 shows the forward flow behavior and the fact that the entire diode body influences the flow. The flow tends to enter the diode, impact the bottom of the diode like a jet, and then get distributed to the top of the diode body before exiting in the forward direction. 


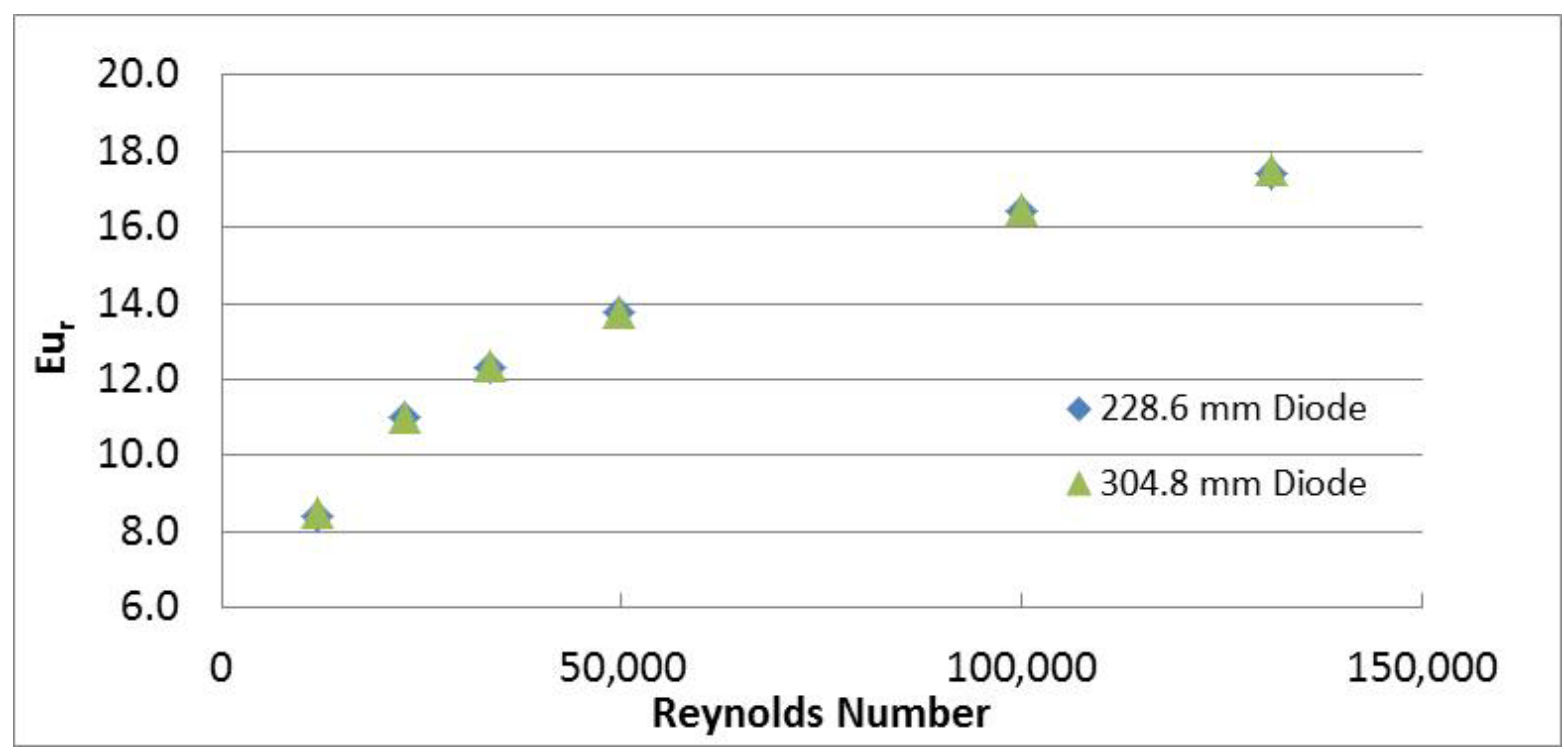

Fig. 14. Euler number in reverse direction versus Reynolds number for $228.6 \mathrm{~mm}$ and $304.8 \mathrm{~mm}$ diodes.

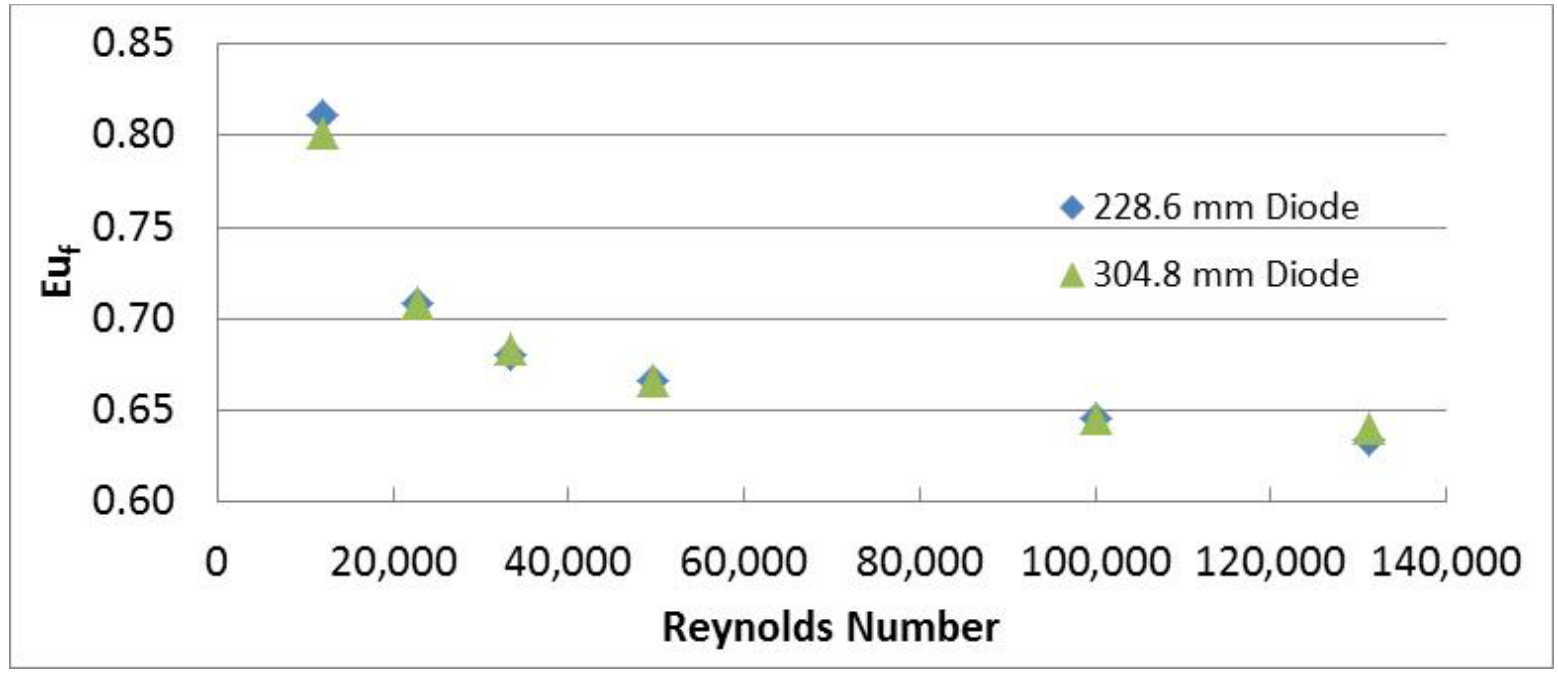

Fig. 15. Euler number in forward direction versus Reynolds number for $228.6 \mathrm{~mm}$ and $304.8 \mathrm{~mm}$ diodes. 


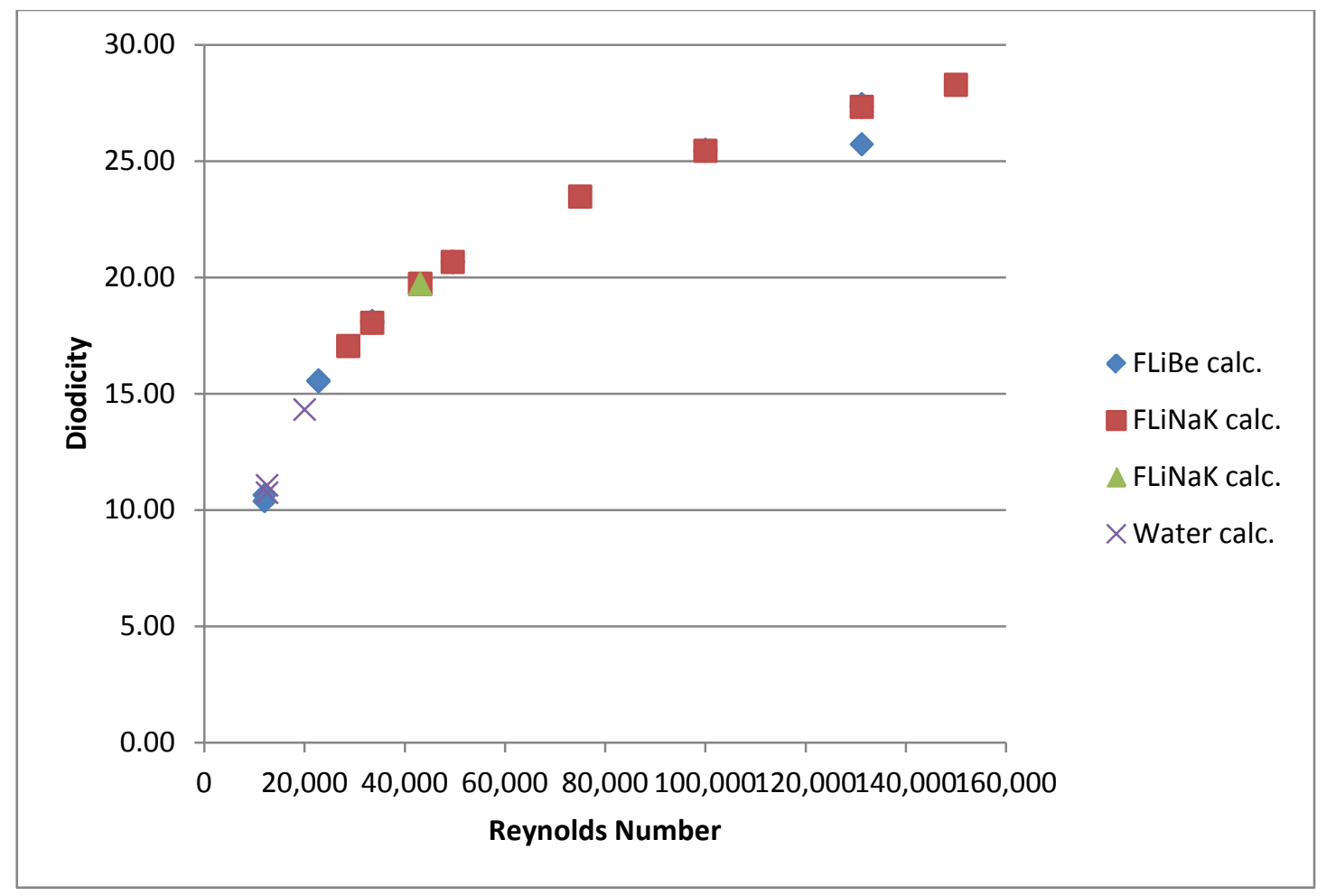

Fig. 16. Results of all CFD runs.

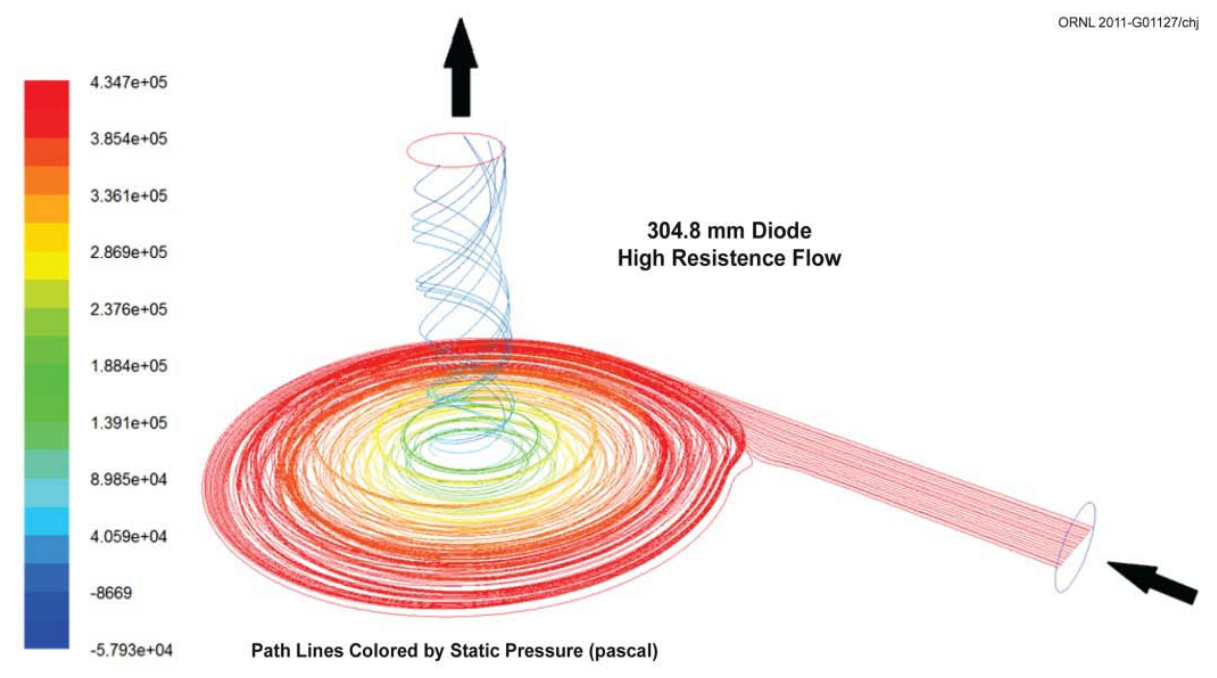

Fig. 17. Path lines of static pressure for FLiBe salt for a static pressure drop of $426 \mathrm{kPa}$ in reverse direction. 


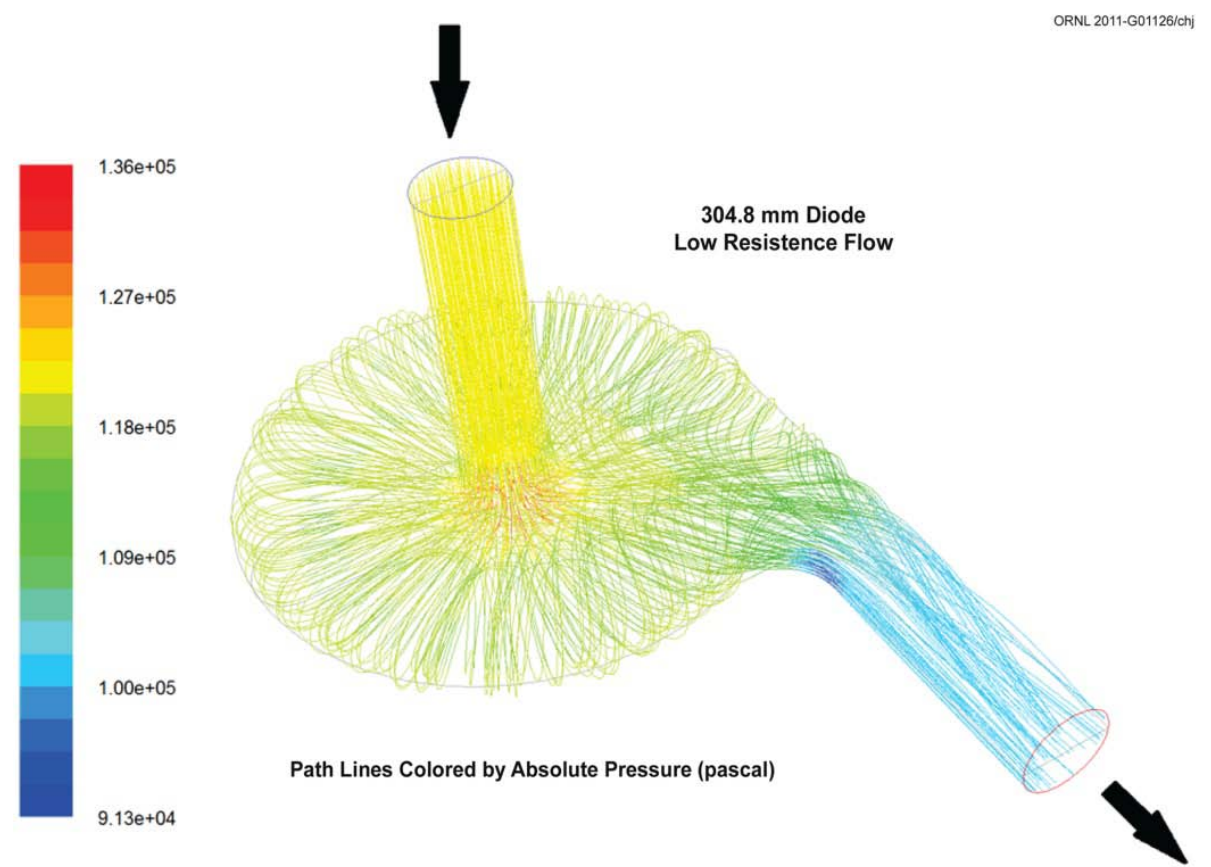

Fig. 18. Path lines of static pressure for FLiBe salt for a static pressure drop of $421 \mathrm{kPa}$ in forward direction.

An additional set of calculations was performed to examine the potential natural circulation behavior of the PB-AHTR under decay heat load to determine if the forward flow pressure drop within the diode was low enough to provide the needed cooling in the core. An EXCEL spreadsheet was used to balance the buoyancy head and the frictional pressure drop in the primary cooling circuit that would be active when the main circulation pumps were not operational, and the DRACS was used to remove decay heat. In these calculations it was assumed that the temperature rise over the core would be $28^{\circ} \mathrm{C}$. This value actually varies over time as the decay heat level in the core changes. This temperature rise was chosen based on RELAP modeling of a somewhat different liquid salt advanced high-temperature reactor design in which $28^{\circ} \mathrm{C}$ was the highest temperature rise during the decay heat transient. Because these scoping calculations were being used only to determine the approximate forward flow characteristics of the flow diode required, it was felt that this approximation was sufficient. The results of the natural circulation calculation indicated that a buoyancy-driven pressure differential of approximately $430 \mathrm{~Pa}$ was available to support flow through the natural circulation circuit. Pressure drops through each of the components in the natural circulation flow path were also calculated in the EXCEL model, and the flow rate was iterated until a balance between buoyancy and frictional pressure drop was achieved. At the conditions stated above, about $50 \mathrm{~kg} / \mathrm{s}$ of flow through the core was supported by natural circulation. This corresponds to approximately $0.5 \%$ of total core power. Additional transient calculations would need to be run to see if this is ultimately sufficient. However, the CFD calculations imply that a $228.6 \mathrm{~mm}$ vortex diode would produce a static head of 17,612 Pa, for a total core flow of approximately $65 \mathrm{~kg} / \mathrm{s}(8.16 \mathrm{~kg} / \mathrm{s} \times 8$ DRACS $=65 \mathrm{~kg} / \mathrm{s}$ from Table 1$)$. If the pressure drop through the diode goes approximately as mass flow rate squared, then at $50 \mathrm{~kg} / \mathrm{s}$ core flow, the pressure drop in the flow diode alone would be 10,400 $\mathrm{Pa}\left([50 / 65]^{2} \times 17,612 \sim 10,400\right)$-much larger than available via buoyancy. Calculations were performed for a larger diode using CFD, indicating that the forward flow pressure drop of a $635 \mathrm{~mm}$ diode would produce a static head of 16,275 $\mathrm{Pa}$, for a total core flow of approximately $480 \mathrm{~kg} / \mathrm{s}(60 \mathrm{~kg} / \mathrm{s} \times 8$ DRACS $=480 \mathrm{~kg} / \mathrm{s}$ from simulation results). If the pressure drop through the diode goes approximately as mass flow rate squared, then at $50 \mathrm{~kg} / \mathrm{s}$ core flow, the pressure drop in the flow diode would be $177 \mathrm{~Pa}\left([50 / 480]^{2} \times 16,275 \sim 177 \mathrm{~Pa}\right)$. This forward pressure drop of about $177 \mathrm{~Pa}$ could probably be accommodated in the design. These estimates imply that at least a $635 \mathrm{~mm}$. vortex diode will be needed for the PB-AHTR design. Additional CFD calculations are 
continuing to examine appropriate diode sizes for the actual reactor. A summary of the natural circulation calculations is presented in Appendix A.

\section{LOOP DIODE DESIGN}

As was discussed above, a $171.45 \mathrm{~mm}$ diameter flow diode appears to be a good fit with the ORNL Liquid Salt Flow Loop design. The diode will be fabricated in two halves, with the halves put together and then welded at the seam. A drawing of one half of the flow diode to be tested is shown in Fig. 19. Both the inlet and outlet ports will be sized to match the inner diameter (ID) of a $25 \mathrm{~mm}$. Schedule 40 pipe [26.6 mm ID], the piping size used in the ORNL Liquid Salt Flow Loop. Welded joints will be used to couple the diode with the loop piping.

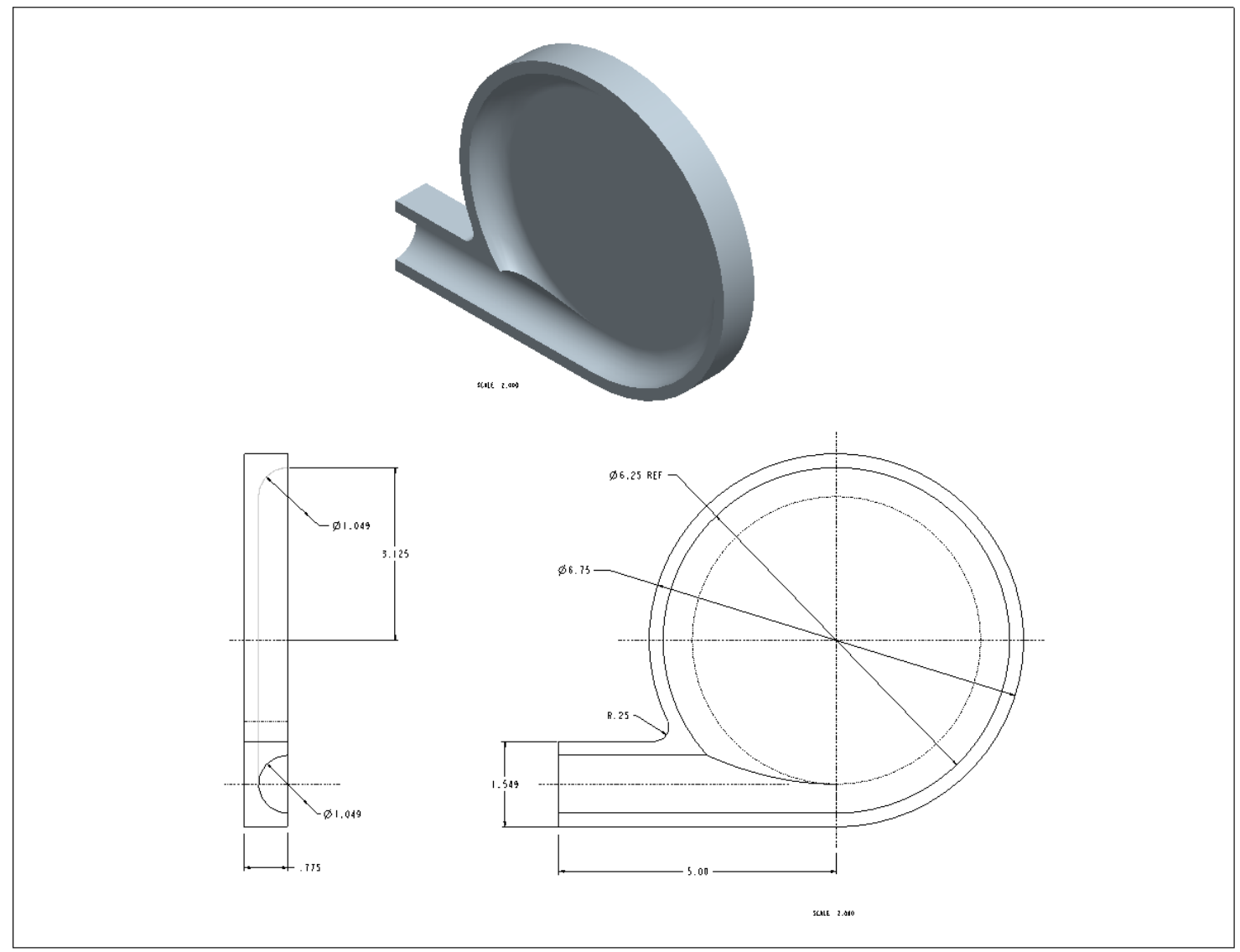

Fig. 19. Drawing of one half of the proposed vortex diode.

A rendering of the loop in its present configuration is presented in Figs. 20 and 21. The pebble bed test section in the figures is the orange-colored object surrounded by an inductive heating coil. This test section will be removed and replaced by a test section that includes the flow diode. Figure 21 shows a closer view of the piping to be replaced for flow diode testing.

In the existing loop the $\mathrm{SiC}$ test section interfaces with the metal portion of the loop (on the pump side) via a slip joint. The metal portion of this joint is slip fit to a section on the pump outlet. To install the vortex diode test section, this joint will be used to attach new piping that supplies FLiNaK flow to the vortex diode. To test the diode in the other flow direction, the diode itself will be cut from the piping, and rewelded in place in the reverse direction. 


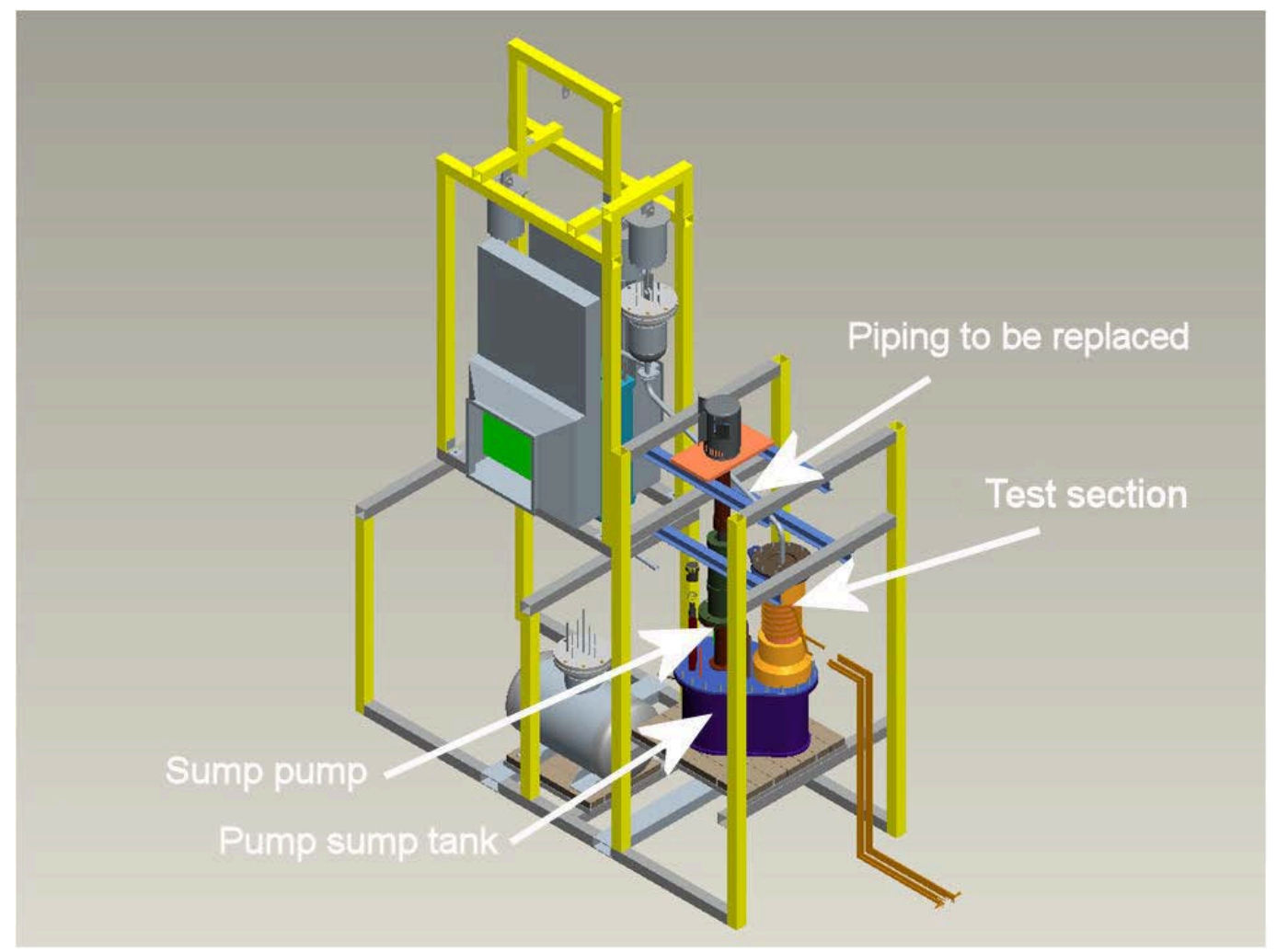

Fig. 20. Overall view of the ORNL Liquid Salt Flow Loop.

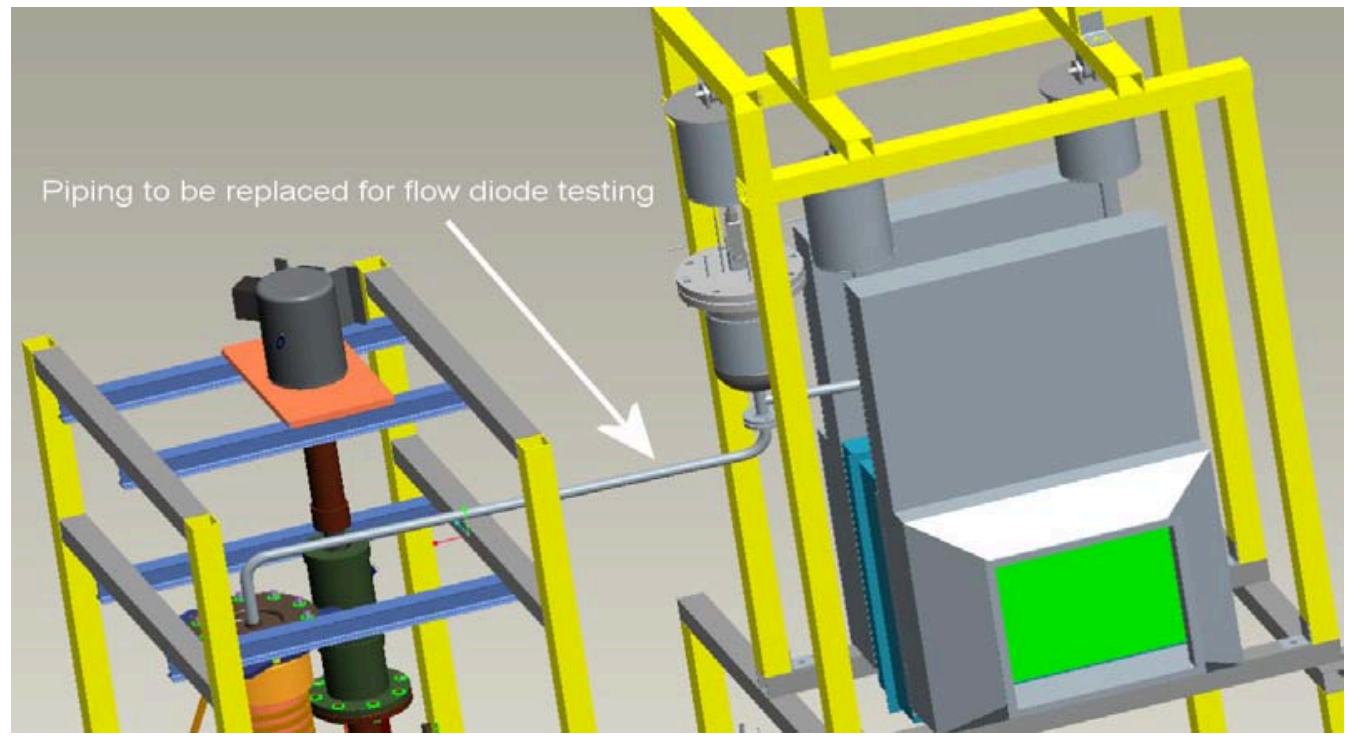

Fig. 21. ORNL Liquid Salt Flow Loop showing test section piping to be replaced by the flow diode test.

Additional instrumentation will also be needed for the flow diode testing. This will include one additional pressure transducer located at the inlet of the diode and a second located at the outlet of the diode to measure pressure differential during operation. For diode testing the inductive heating system presently used to supply power to the existing test section will be removed. Loop heating and loop temperature maintenance will be performed using trace heaters located around the loop. The control necessary for this heating during diode operation has yet to be assessed. 


\section{WATER EXPERIMENTATION}

Test Loop: A water experiment has been conducted to determine the diodicity of a $171.45 \mathrm{~mm}$ diode, the size expected to be used in the Liquid Salt Flow Loop. The experimental water loop used for this testing is a pumped loop facility that is capable of providing up to $160 \mathrm{~m}^{3} / \mathrm{h}$ of water at $15 \mathrm{~m}$ of water head. It consists of a $1136 \mathrm{~L}$ water storage tank that operates at atmospheric pressure and acts as an inlet sump for the pump suction. The polyvinyl chloride loop piping is made up of a combination of $150 \mathrm{~mm}$, $75 \mathrm{~mm}$, and $50 \mathrm{~mm}$ piping runs. A loop rendering is shown in Fig. 22. A Bell and Gossett 1510 centrifugal pump is driven by a 15 hp, 1800 rpm US Electrical Motors electric motor. A Robicon 454GT variable-speed inductive drive unit is used to vary pump revolutions per minute and flow through the loop. The pump curve for the Bell and Gossett pump is shown in Fig. 23. The pump installed in the loop uses a $216 \mathrm{~mm}$ impeller. Maximum flow rates used for flow diode testing were only $10.2 \mathrm{~m}^{3} / \mathrm{h}$, and the pump therefore operated at the lower end of the pump flow curve.

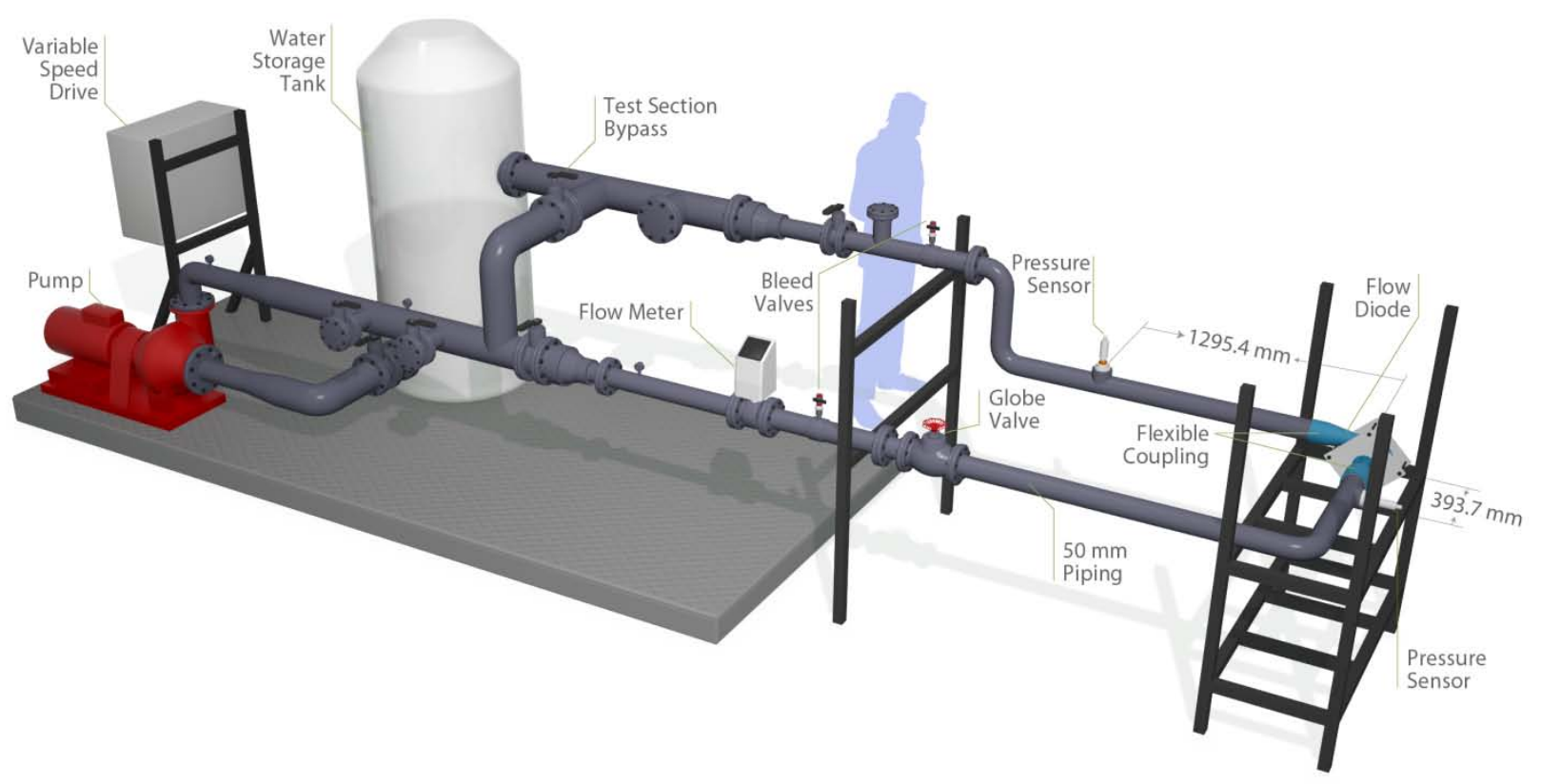

Fig. 22. Water loop used to perform flow diode testing.

The flow diode test article was placed in the $50 \mathrm{~mm}$ diameter line and located in the upper right corner of the piping shown in Fig. 19. A Danfoss MAGFLOW MAG 3000 magnetic flow sensor and MAG 3100 signal convertor were used to measure the water flow rate entering the fluidic diode. The flow meter was calibrated in situ by removing the flow diode and timing the flow of water into a $208 \mathrm{~L}$ drum. The calibration covered multiple flow rates up to the maximum flow rate expected during testing i.e., up to $10.2 \mathrm{~m}^{3} / \mathrm{h}$ ). Flow meter accuracy is $0.25 \%$ of reading. Two Omega PX209-060GI 0-60 psig pressure transducers were used to measure pressure before and after the flow diode. Transducers were calibrated against a National Institute of Standards and Technology calibration standard. The pressure transducers have an accuracy of $0.25 \%$ full scale, including linearity, hysteresis, and repeatability. An IOtech personal daq156 data acquisition system along with a Windows-based laptop computer were used to acquire flow and pressure data during testing. 


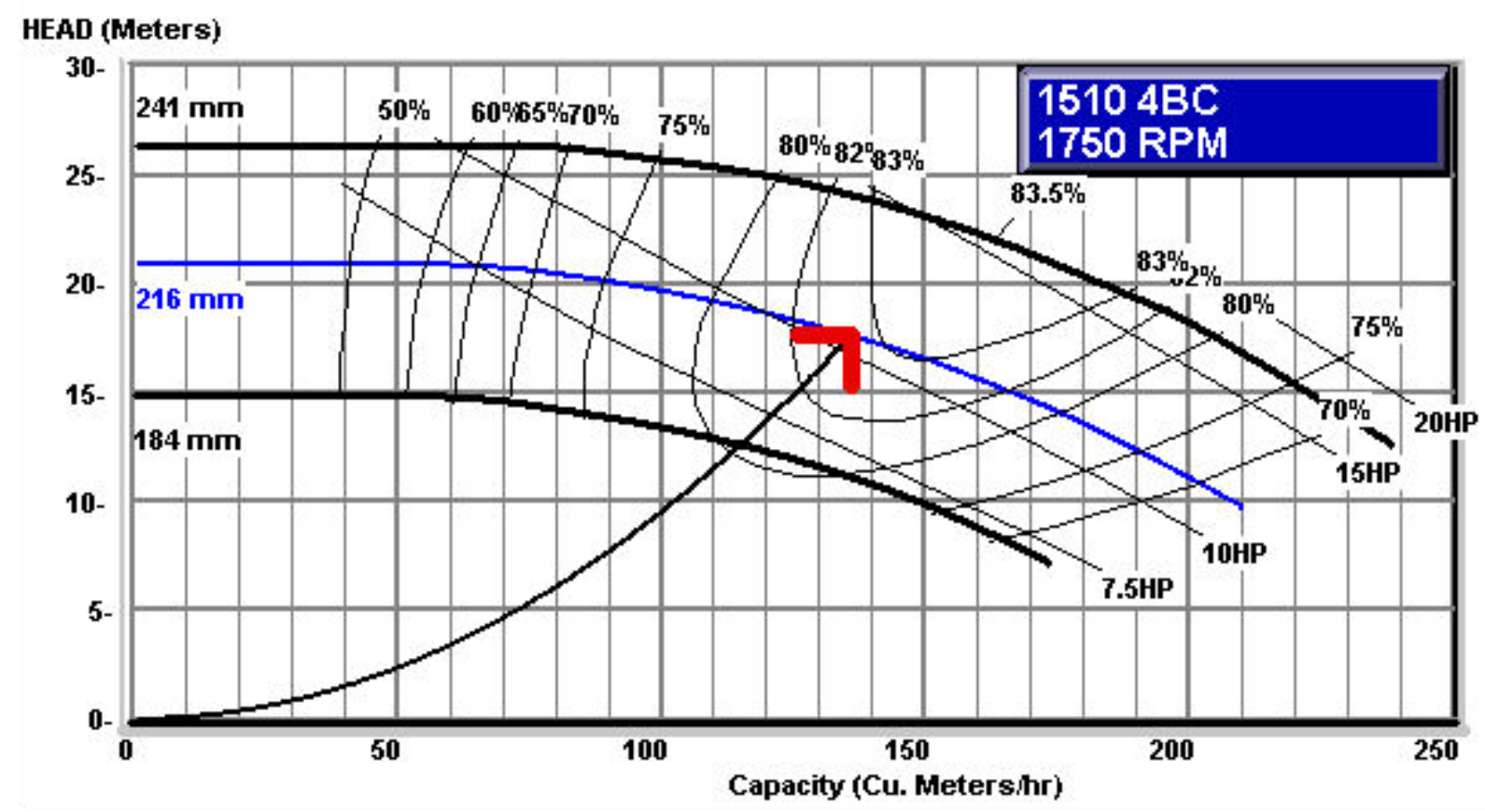

Fig. 23. Bell and Gossett pump curve (216 $\mathrm{mm}$ impeller used in testing).

Loop operation: For reverse flow testing, the tangential port of the diode was oriented in the loop so that it acted as the inlet to the diode. Testing in the reverse flow direction of the fluidic diode consisted of aligning the loop valving so that the pump bypass valve was closed and all other valves in the system were open. This was done to obtain the highest possible pressure drop through the flow diode. The pump speed was increased until the desired flow rate through the diode was obtained, and data were taken for approximately $20 \mathrm{~s}$. The data acquisition rate was approximately $2 \mathrm{~Hz}$, so about 30 to 40 data points were taken at each flow rate. These data were then averaged to arrive at a single data point consisting of an individual flow rate and pressure drop combination.

After data were taken in the reverse flow direction, the flow diode was removed from the loop and reinstalled so that the axial port of the diode acted as the inlet. The loop was runs for the reverse flow operation except that the pump bypass valve was opened approximately 15\% during forward flow testing. The pump speed was set to establish flow rates as close as possible to those taken during reverse flow testing. The loop globe valve was then adjusted to fine tune the flow even further. The data for the forward flow testing were taken in a similar manner to that discussed for the reverse flow tests.

Test article: The diode design shown in Fig. 12 was used for water testing. This diode was fabricated from acrylonitrile butadiene-styrene plastic using a three-dimensional printer system manufactured by Dimension. The mechanical design of the diode was made using a computer-aided design package, ProEngineer. A .stl file was generated with Pro-Engineer and imported into the Dimension Elite P11387 printer system. Printing took approximately $4 \mathrm{~d}$, and the resulting component was soaked in a caustic bath overnight to remove support material used by the printer system during fabrication of the diode. The resulting part has no seams and requires no plastic welding after fabrication. A picture of the diode as fabricated is shown in Fig. 24.

The printing process creates a high-fidelity geometry that is somewhat porous. To make it watertight, it is necessary to seal the porosity in the plastic. To do this, we used a vacuum epoxy process. The diode was placed in an open-top plastic bag, which was then filled with an unfilled high-solid-content epoxy resin manufactured by BJB Enterprises. The bag that held the diode and uncured epoxy was then placed in a small vacuum chamber (Fig. 25). A vacuum was pulled and released multiple times to ensure that all pores in the diode were filled. At the end of the vacuum process, the remaining epoxy was drained from 


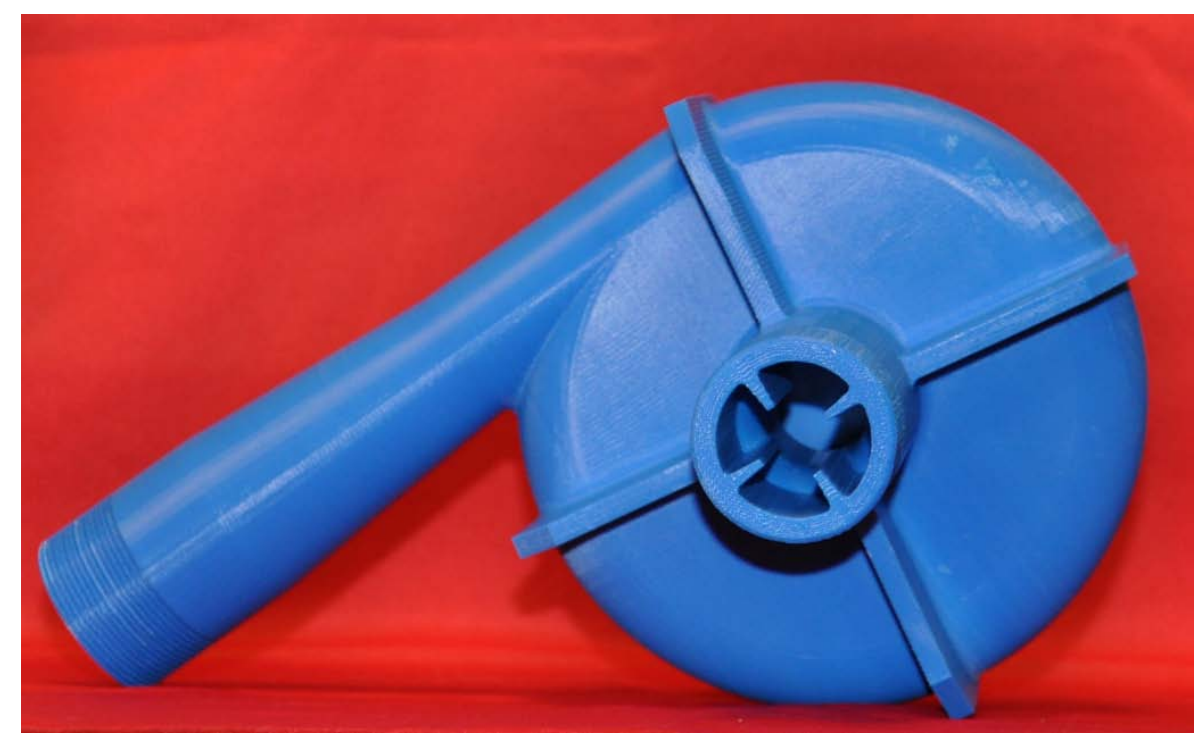

Fig. 24. As-fabricated flow diode.

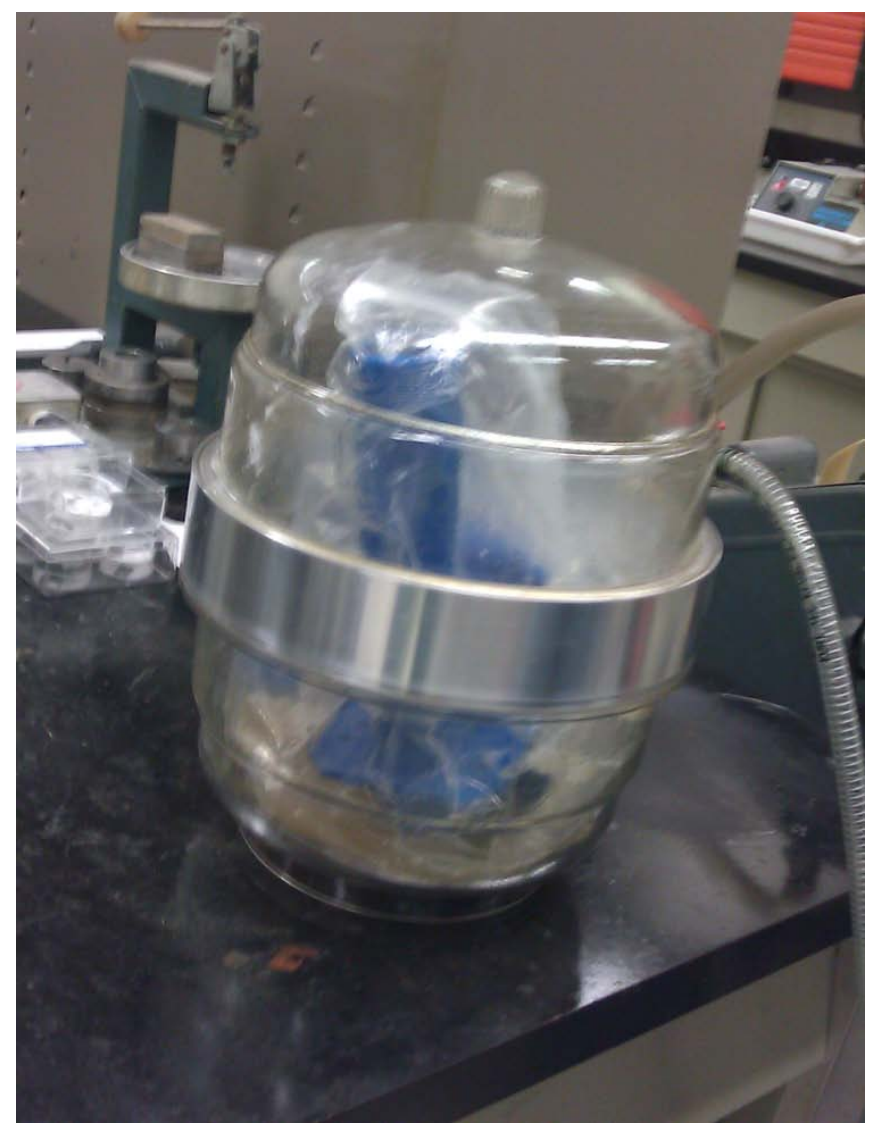

Fig. 25. Epoxy filling pores in the plastic flow diode.

the diode and the epoxy-filled diode was hung to cure in such a way as to ensure that no epoxy pooling would occur during the draining/curing process. The diode was left to cure for $24 \mathrm{~h}$ before being used. Even after this process, a few pores still remained in the plastic, and these were then coated with additional epoxy using a surface application to completely seal the diode. The diode/backing plate 
assembly was then pressure tested at $0.3 \mathrm{MPa}$ to ensure structural integrity before being installed in the water loop.

The geometry of the diode is such that it can be conveniently installed similar to an elbow in the loop. It was installed in the water loop using flexible couplings with standard hose clamps. This configuration allowed the diode to be easily removed and installed for testing in both the forward and reverse directions. Figure 26 is a picture of the flow diode as it was installed in the water loop for reverse flow testing.

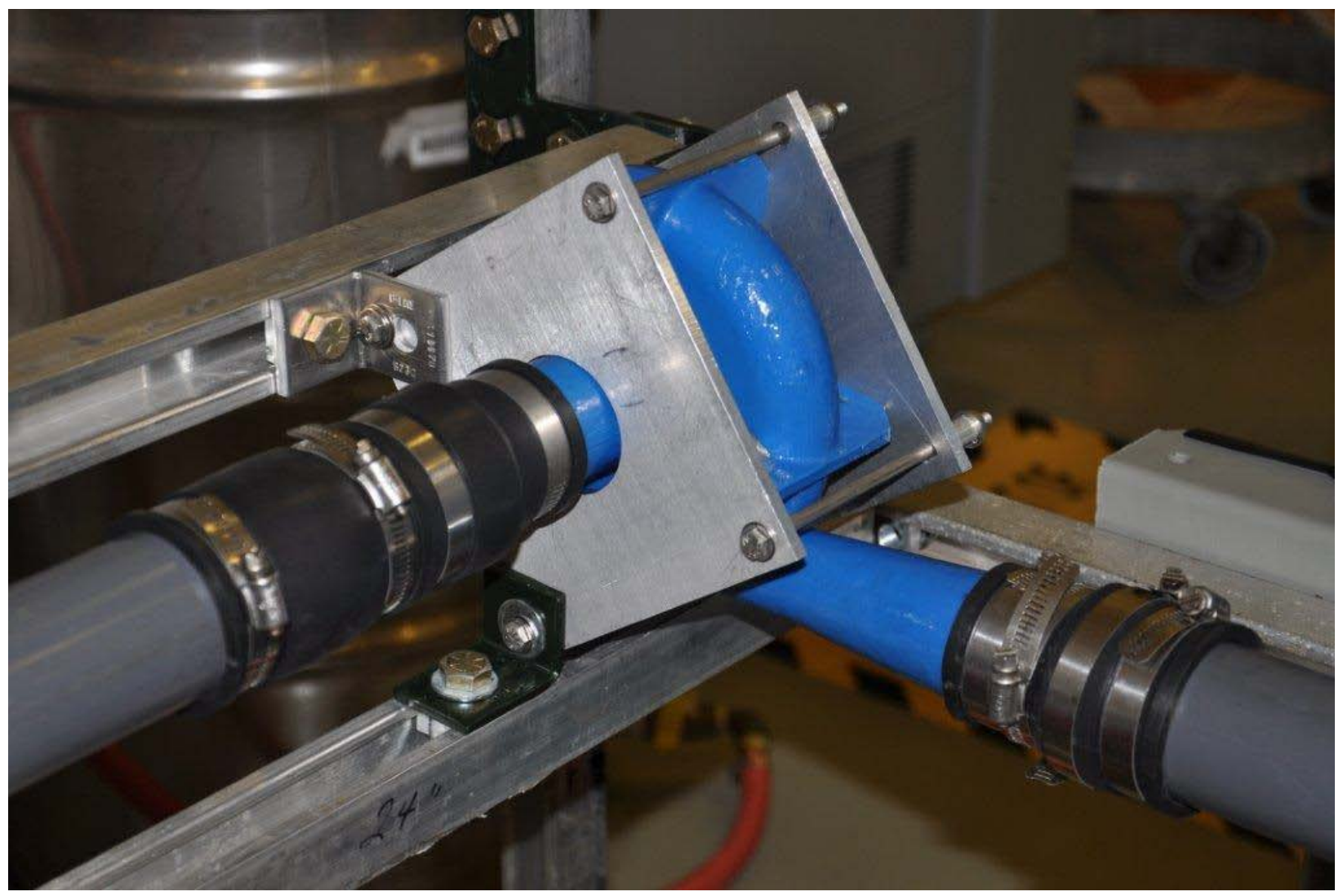

Fig. 26. Flow diode installed in the water loop.

Experimental results: Testing of the diode produced data for inlet pressure, outlet pressure, and water flow. Forward flow testing was performed in such a way as to match flow rates tested during reverse flow testing so that a direct measurement of diocicity could be made by creating ratios of the pressure drops. However, the forward and reverse flow rates did not exactly match. To experimentally determine diodicity as closely as possible, individual forward flow rates were calculated (to exactly match those of the reverse flow tests) by interpolating between forward flow data points. Additionally, the pressure transducers were located a distance from the inlet and outlet of the diode to ensure that local flow patterns near the diode would not affect the pressure measurements. Pressures used for calculating Euler number and diodicity were corrected to account for pressure drops between the diode and the pressure measurement locations in the loop.

Results of forward flow testing are presented in Table 5. This table shows the measured flow rates and pressure drops for all tests conducted in the forward direction. Similarly, Table 6 shows all of the measured data taken in the reverse flow direction. 
Table 5. Forward flow diode data

\begin{tabular}{cccc}
\hline Flow $\left(\mathbf{m}^{3} \mathbf{h}\right)$ & $\begin{array}{c}\text { Inlet pressure } \\
\mathbf{( M P a )}\end{array}$ & $\begin{array}{c}\text { Outlet pressure } \\
\mathbf{( M P a )}\end{array}$ & $\mathbf{E u}$ \\
\hline 2.285 & $1.006 \mathrm{E}-02$ & $7.279 \mathrm{E}-03$ & 2.142 \\
2.305 & $1.002 \mathrm{E}-02$ & $7.118 \mathrm{E}-03$ & 2.198 \\
2.763 & $1.083 \mathrm{E}-02$ & $7.533 \mathrm{E}-03$ & 1.711 \\
2.766 & $1.096 \mathrm{E}-02$ & $7.381 \mathrm{E}-03$ & 1.855 \\
2.795 & $1.118 \mathrm{E}-02$ & $7.845 \mathrm{E}-03$ & 1.688 \\
3.302 & $1.178 \mathrm{E}-02$ & $7.417 \mathrm{E}-03$ & 1.567 \\
3.333 & $1.174 \mathrm{E}-02$ & $7.506 \mathrm{E}-03$ & 1.492 \\
3.339 & $1.173 \mathrm{E}-02$ & $7.594 \mathrm{E}-03$ & 1.450 \\
3.340 & $1.186 \mathrm{E}-02$ & $7.840 \mathrm{E}-03$ & 1.407 \\
3.819 & $1.260 \mathrm{E}-02$ & $7.799 \mathrm{E}-03$ & 1.276 \\
3.828 & $1.282 \mathrm{E}-02$ & $7.953 \mathrm{E}-03$ & 1.288 \\
3.843 & $1.286 \mathrm{E}-02$ & $7.752 \mathrm{E}-03$ & 1.344 \\
3.868 & $1.300 \mathrm{E}-02$ & $7.647 \mathrm{E}-03$ & 1.394 \\
4.434 & $1.396 \mathrm{E}-02$ & $7.965 \mathrm{E}-03$ & 1.177 \\
4.469 & $1.438 \mathrm{E}-02$ & $8.097 \mathrm{E}-03$ & 1.216 \\
4.489 & $1.459 \mathrm{E}-02$ & $8.083 \mathrm{E}-03$ & 1.251 \\
4.496 & $1.441 \mathrm{E}-02$ & $8.254 \mathrm{E}-03$ & 1.176 \\
5.072 & $1.550 \mathrm{E}-02$ & $7.981 \mathrm{E}-03$ & 1.127 \\
5.111 & $1.577 \mathrm{E}-02$ & $7.765 \mathrm{E}-03$ & 1.186 \\
5.150 & $1.607 \mathrm{E}-02$ & $7.805 \mathrm{E}-03$ & 1.206 \\
5.192 & $1.620 \mathrm{E}-02$ & $8.282 \mathrm{E}-03$ & 1.133 \\
5.411 & $1.652 \mathrm{E}-02$ & $8.112 \mathrm{E}-03$ & 1.108 \\
5.445 & $1.677 \mathrm{E}-02$ & $7.927 \mathrm{E}-03$ & 1.153 \\
5.672 & $1.738 \mathrm{E}-02$ & $8.209 \mathrm{E}-03$ & 1.100 \\
5.727 & $1.755 \mathrm{E}-02$ & $7.940 \mathrm{E}-03$ & 1.133 \\
2.285 & $1.006 \mathrm{E}-02$ & $7.279 \mathrm{E}-03$ & 2.142 \\
2.305 & $1.002 \mathrm{E}-02$ & $7.118 \mathrm{E}-03$ & 2.198 \\
\hline
\end{tabular}


Table 6. Reverse flow diode data

\begin{tabular}{|c|c|c|c|}
\hline Flow $\left(\mathrm{m}^{3} / \mathbf{h}\right)$ & $\begin{array}{c}\text { Inlet pressure } \\
(\mathrm{MPa})\end{array}$ & $\begin{array}{c}\text { Outlet pressure } \\
\text { (MPa) }\end{array}$ & Eu \\
\hline 2.256 & $4.607 \mathrm{E}-02$ & $6.515 \mathrm{E}-03$ & 31.458 \\
\hline 2.277 & 4.682E-02 & $5.534 \mathrm{E}-03$ & 32.240 \\
\hline 2.285 & 4.632E-02 & 5.531E-03 & 31.615 \\
\hline 2.776 & 6.807E-02 & 5.576E-03 & 32.800 \\
\hline 2.792 & 6.761E-02 & $6.438 \mathrm{E}-03$ & 31.728 \\
\hline 2.794 & 6.766E-02 & $6.516 \mathrm{E}-03$ & 31.671 \\
\hline 2.806 & 6.881E-02 & 5.513E-03 & 32.504 \\
\hline 3.333 & $9.547 \mathrm{E}-02$ & $5.541 \mathrm{E}-03$ & 32.727 \\
\hline 3.352 & $9.416 \mathrm{E}-02$ & $6.581 \mathrm{E}-03$ & 31.513 \\
\hline 3.367 & 9.386E-02 & 6.486E-03 & 31.151 \\
\hline 3.369 & $9.521 \mathrm{E}-02$ & $5.538 \mathrm{E}-03$ & 31.936 \\
\hline 3.868 & $1.246 \mathrm{E}-01$ & 5.603E-03 & 32.157 \\
\hline 3.875 & $1.263 \mathrm{E}-01$ & $5.512 \mathrm{E}-03$ & 32.511 \\
\hline 3.910 & $1.248 \mathrm{E}-01$ & 6.621E-03 & 31.229 \\
\hline 3.913 & $1.246 \mathrm{E}-01$ & $6.564 \mathrm{E}-03$ & 31.161 \\
\hline 4.118 & $1.438 \mathrm{E}-01$ & 6.606E-03 & 32.702 \\
\hline 4.174 & $1.439 \mathrm{E}-01$ & $6.509 \mathrm{E}-03$ & 31.880 \\
\hline 4.369 & $1.604 \mathrm{E}-01$ & 6.607E-03 & 32.567 \\
\hline 4.465 & $1.620 \mathrm{E}-01$ & 5.592E-03 & 31.722 \\
\hline 4.482 & $1.612 \mathrm{E}-01$ & $5.629 \mathrm{E}-03$ & 31.308 \\
\hline 4.513 & $1.623 \mathrm{E}-01$ & $6.628 \mathrm{E}-03$ & 30.897 \\
\hline 5.104 & 2.029E-01 & 5.724E-03 & 30.588 \\
\hline 5.123 & $2.030 \mathrm{E}-01$ & $6.624 \mathrm{E}-03$ & 30.245 \\
\hline 5.123 & $2.021 \mathrm{E}-01$ & 5.541E-03 & 30.273 \\
\hline 5.135 & 2.025E-01 & $6.472 \mathrm{E}-03$ & 30.058 \\
\hline 5.446 & $2.255 \mathrm{E}-01$ & $6.611 \mathrm{E}-03$ & 29.819 \\
\hline 5.448 & $2.244 \mathrm{E}-01$ & $5.496 \mathrm{E}-03$ & 29.819 \\
\hline 5.679 & 2.455E-01 & $6.620 \mathrm{E}-03$ & 29.937 \\
\hline 5.745 & $2.484 \mathrm{E}-01$ & 6.699E-03 & 29.597 \\
\hline 5.749 & $2.480 \mathrm{E}-01$ & $5.780 \mathrm{E}-03$ & 29.615 \\
\hline 5.759 & $2.481 \mathrm{E}-01$ & $5.621 \mathrm{E}-03$ & 29.550 \\
\hline
\end{tabular}


The forward- and reverse-flow Euler numbers are plotted in Fig. 27. They display the characteristic behavior as expected from literature results and as is predicted by the CFD calculations above. The reverse-flow Euler number tends to increase with Reynolds number and then flatten out or slightly decrease, and the forward-flow Euler number decreases with Reynolds number.

The experimentally determined diodicity is plotted against Reynolds number in Fig. 28. The diodicity increases with Reynolds number up to a value of about 45,000 and then remains about constant. This general behavior with Reynolds number is consistent with both the literature and the CFD calculations presented above. Some subtle features of this curve, such as the slight change in slope at a Reynolds number of $\sim 45,000$, have yet to be investigated.

Comparison between experiment and calculation: Figure 29 replots the experimental data shown in Fig. 28 along with all of the CFD results (only results from k- $\varepsilon$ realizable model shown). As this figure indicates, the experimental diodicity (gold circles) increases more rapidly with Reynolds number than do the CFD results. Also shown on this figure are the calculated results for the $171.45 \mathrm{~mm}$ diameter diode with the modifications discussed above (blue star). These results should be a direct comparison with the experimental results because the design of the experimental diode was modeled directly using CFD for this point. As the figure indicates, the predicted diodicity for this diode is significantly different than that experimentally determined. Differences between experimental and predicted diode performance are presently being investigated.

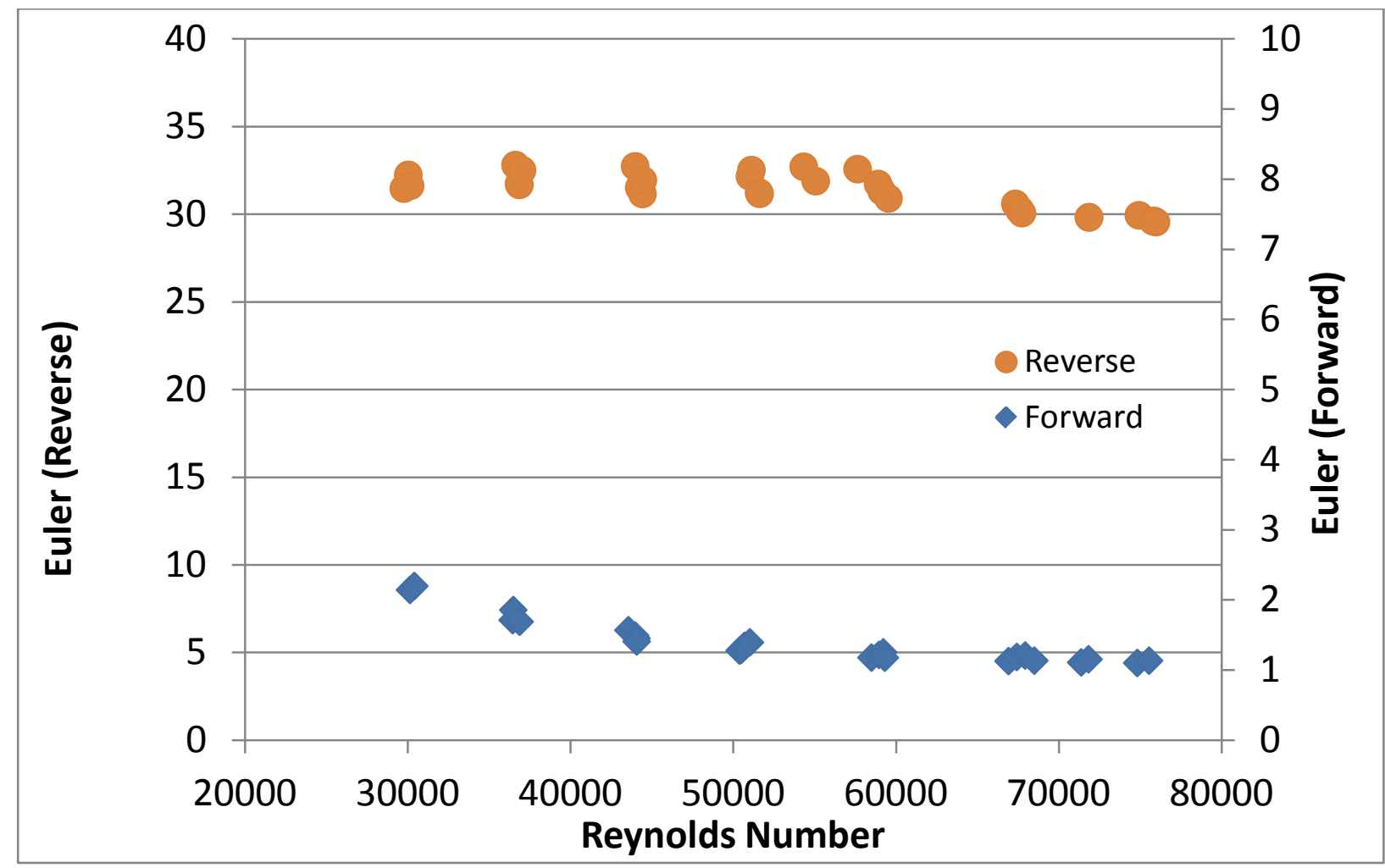

Fig. 27. Forward- and reverse-flow Euler numbers from test data. 


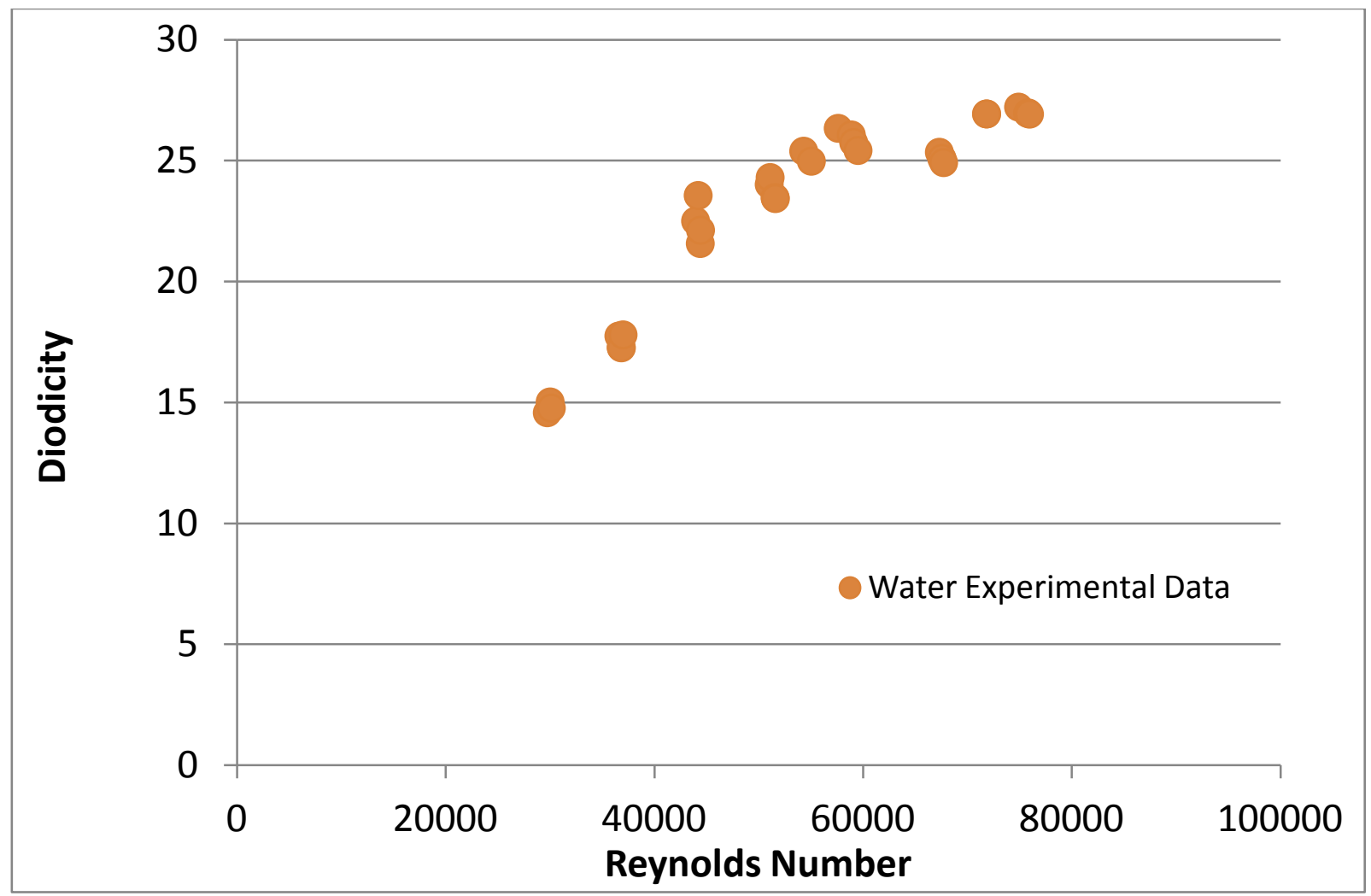

Fig. 28. Experimentally measured diodicity.

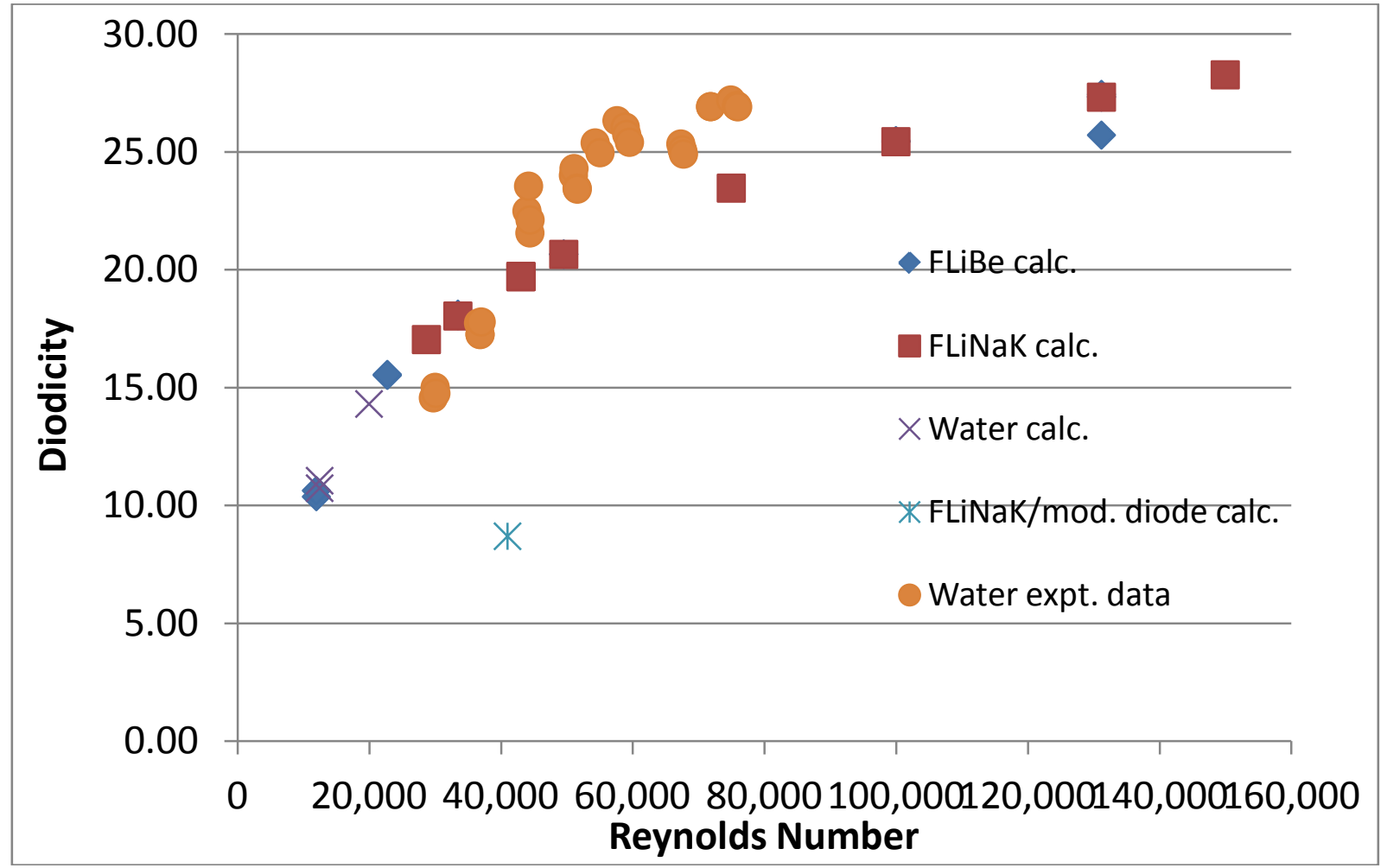

Fig. 29. Comparison of experimental data and CFD predictions. 


\section{SUMMARY}

A series of CFD calculations has been performed to investigate the behavior of a fluidic diode that uses vortex flow to increase flow resistance through the device. Multiple fluids have been investigated along with diode size and flow through the diode. These calculations have shown that for the diode sizes investigated, the calculated results of diodicity can all be reasonably collapsed to a single function of diode Reynolds number. Additionally, an experimental program including a water loop was used to characterize the performance of a $171.45 \mathrm{~mm}$ diode. Although the performance of the experimental diode showed the same general behavior as the CFD results, when directly compared to CFD results, some discrepancies were observed. Additional investigation (both calculated and experimental) is needed to completely understand the differences. In preparation for testing a vortex diode using FLiNaK as the working fluid, a design for both the flow diode and loop modifications has been presented that will allow testing in the Liquid Salt Flow Loop.

\section{REFERENCES}

1. R. Zobel, “Experiments on a Hydraulic Reversing Throat,” Mitt .Hydraulic Munich 8(19), 1-47 (1930).

2. N. Tesla, "Valvular Conduit.” US Patent 13,295,59, February 3, 1920.

3. P. Bardet, E. Blandford, M. Fratoni, A. Niquelle, E. Greenspan, and P.F. Peterson, "Design, Analysis and Development of the Modular PB-AHTR,” Proc. ICAPP 2008, Anaheim, CA (2008).

4. A.A. Kulkarni, V.V. Ranake, R. Rajeev, and S.B. Koganti, "CFD Simulation of Flow in Vortex Diodes," AIChE Journal 54(5) (May 2008).

5. A.A. Kulkarni, V.V. Ranake, R. Rajeev, and S. Koganti, "Pressure Drop Across Vortex Diodes: Experiments and Design Guidelines,” J. Chemical Engineering Science 64, 1285-92 (2009).

6. G.H. Priestman, “A Study of Vortex Throttles, Part 1, Experimental,” Proc. Inst. Mech. Eng. 21(C5), 331-6 (1987).

7. G.H. Priestman and J.R. Tippetts, "Development and Potential for Power Fluidics for Process Flow Control,” Chem. Eng. Res. Des. 62, 67-80 (1984).

8. FLUENT User's Manual, , Version 6.3, FLUENT Inc., available at http://my.fit.edu/itresources/ manuals/fluent6.3/help/pdf/ug/pdf.htm.

9. Z.N. Yang and G.H. Priestman, "Internal Flow Modeling of Vortex Throttles," Proc. Instn. Mech. Engrs. 205, 405-12 (1991).

10. Yin, J., Tiao, L., and Wong, L., "Large Eddy Simulation of Unsteady Flow in a Vortex Diode," Nuclear Engineering and Design, 240, 970-974 (2010).

11. GAMBIT Command Reference Guide, FLUENT Inc., available at http://202.118.250.111:8080/ fluent/Gambit13_help/command_reference/crtoc.htm. 
APPENDIX A

NATURAL CIRCULATION CALCULATIONS 



\section{APPENDIX A \\ NATURAL CIRCULATION CALCULATIONS}

To estimate the flow through the Pebble Bed Advanced High Temperature Reactor (PB-AHTR) core and direct reactor auxiliary cooling system (DRACS) during shutdown operation, an EXCEL calculation sheet was developed to balance the buoyancy head with the various pressure drops around the natural circulation flow loop. A sketch of the geometry used is shown in Fig. A1. The natural circulation flow path is indicated by the arrows in the figure. The path was broken into six sections. Table A1 shows the paths and geometry assumed in the calculations. For these simplified calculations, it was assumed that the horizontal flow paths were large enough that their flow resistance was low.

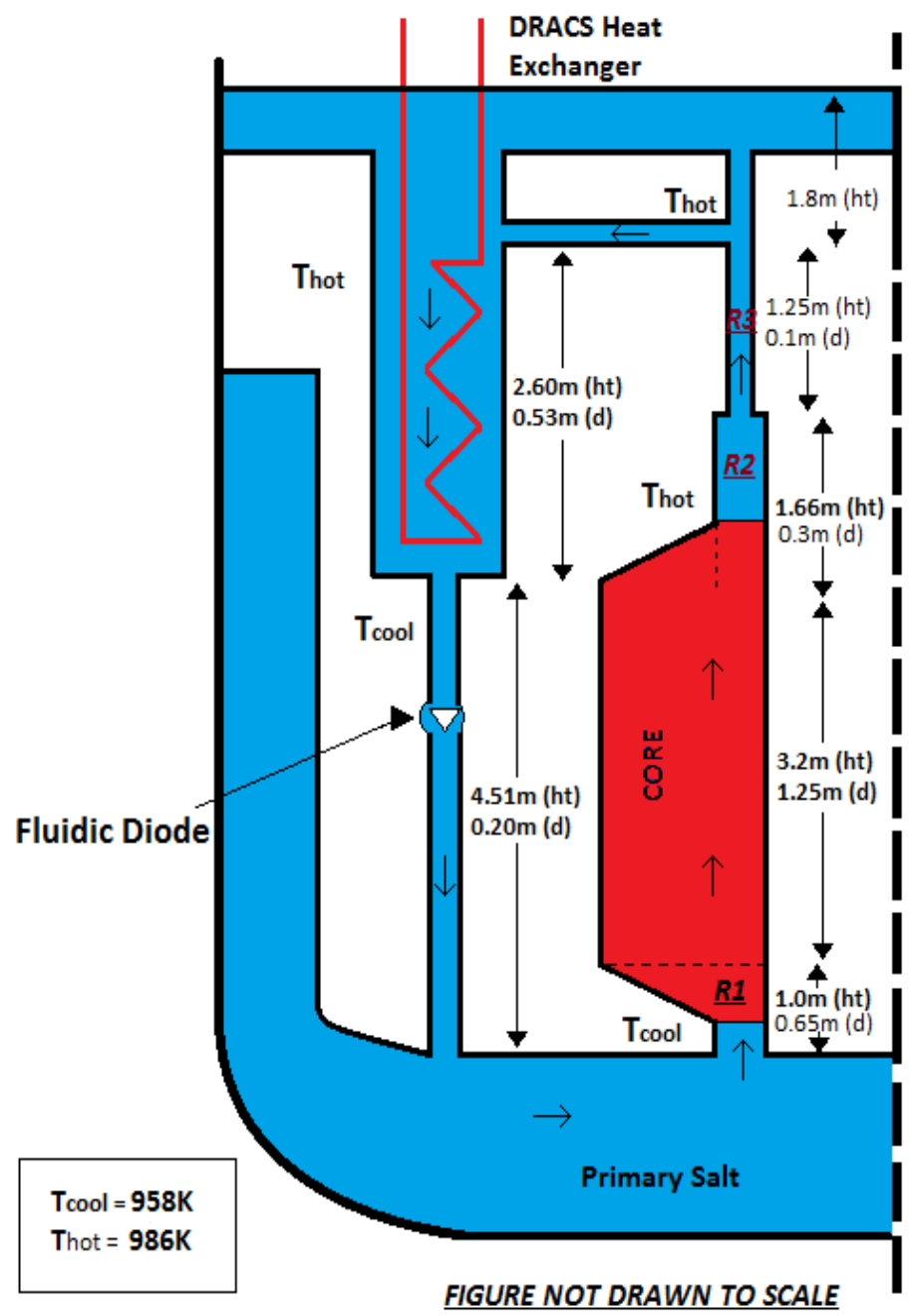

Fig. A1. Geometry used in natural circulation calculations.

Table A1. Flow path geometry assumed in calculations

\begin{tabular}{cccc}
\hline Component & Height (m) & Diameter $(\mathbf{m})$ & Temperature \\
\hline R1 & 1 & 0.65 & Cold \\
Core & 3.2 & 0.198 & Average \\
R2 & 1.66 & 0.3 & Hot \\
R3 & 1.25 & 0.1 & Hot \\
DRACS & 2.6 & & Average \\
D1 & 4.51 & 0.2 & Cold \\
\hline
\end{tabular}


For the core region, flow through a packed pebble bed was assumed, and pressure drop was calculated using the Ergun equation:

$$
\Delta \mathrm{P}_{\mathrm{b}}=\rho \mathrm{V}_{0}{ }^{2 *}\left(150 *(1-\varepsilon)^{2} / \mathrm{Re}_{\mathrm{p}} / \varepsilon^{3}+1.75^{*}(1-\varepsilon) / \varepsilon^{3}\right) * \mathrm{~L} / \mathrm{D}_{\mathrm{p}},
$$

where

$$
\begin{aligned}
& \Delta \mathrm{P}_{\mathrm{b}}=\text { pressure drop through the bed } \\
& \rho=\text { fluid density } \\
& V_{0}=\text { superficial velocity through the bed } \\
& \varepsilon=\text { bed liquid fraction (assumed to be } 0.4) \\
& \mathrm{L}=\text { bed length } \\
& D_{p}=\text { pebble diameter } \\
& \operatorname{Re}_{\mathrm{p}}=\text { pebble Reynolds number }\left(\rho \mathrm{V}_{0} \mathrm{D}_{\mathrm{p}} / \mu\right) \\
& \mu=\text { fluid viscosity. }
\end{aligned}
$$

The buoyancy force was calculated around the flow path:

$$
\Delta \mathrm{P}_{\text {bouy }}=\rho_{\mathrm{c}} g \mathrm{~h}_{\mathrm{d} 1}+\rho_{\mathrm{av}} \mathrm{gh}_{\mathrm{DHX}}-\rho_{\mathrm{h}} \mathrm{gh}_{\mathrm{r} 3}-\rho_{\mathrm{h}} \mathrm{gh} \mathrm{r} 2-\rho_{\mathrm{av}} \mathrm{gh}_{\mathrm{c}}-\rho_{\mathrm{c}} \mathrm{gh}_{\mathrm{r} 1},
$$

where

$$
\begin{aligned}
& \rho_{\mathrm{c}}=\text { cold fluid density } \\
& \rho_{\mathrm{h}}=\text { hot fluid density } \\
& \rho_{\mathrm{av}}=\text { average fluid density (average of hot and cold fluid density) } \\
& \mathrm{h}=\text { height of segment } \\
& \mathrm{g}=\text { acceleration of gravity } \\
& \begin{array}{ll}
\text { Subscripts: } \quad \mathrm{r} 1=\text { riser } \mathrm{r} 1 \\
\mathrm{r} 2=\text { riser } \mathrm{r} \\
\mathrm{r} 3=\text { riser } \mathrm{r} 3 \\
\text { DHX = DRACS salt to salt heat exchanger } \\
\mathrm{d} 1=\text { downcomer } \\
\mathrm{c}=\text { core. }
\end{array}
\end{aligned}
$$

The frictional pressure drop in each segment was also calculated as

$$
\begin{gathered}
\Delta \mathrm{P}_{\mathrm{f}}=\quad 4 \mathrm{f}\left(\rho_{\mathrm{c}} \mathrm{V}_{\mathrm{r} 1}^{2} / 2\right)\left(\mathrm{h}_{\mathrm{r} 1} / \mathrm{D}_{\mathrm{r} 1}\right)+\Delta \mathrm{P}_{\mathrm{b}}+4 \mathrm{f}\left(\rho_{\mathrm{h}} \mathrm{V}_{\mathrm{r} 2}^{2} / 2\right)\left(\mathrm{h}_{\mathrm{r} 2} / \mathrm{D}_{\mathrm{r} 2}\right)+4 \mathrm{f}\left(\rho_{\mathrm{h}} \mathrm{V}_{\mathrm{r} 3}^{2} / 2\right)\left(\mathrm{h}_{\mathrm{r} 3} / \mathrm{D}_{\mathrm{r} 3}\right)+\Delta \mathrm{P}_{\mathrm{DHX}}+ \\
4 \mathrm{f}\left(\rho_{\mathrm{c}} \mathrm{V}_{\mathrm{d} 1}^{2} / 2\right)\left(\mathrm{h}_{\mathrm{d} 1} / \mathrm{D}_{\mathrm{d} 1}\right)+\Delta \mathrm{P}_{\mathrm{v}},
\end{gathered}
$$

where

$$
\begin{aligned}
& \mathrm{V}=\text { fluid velocity } \\
& \mathrm{f}=\text { turbulent friction factor }\left(0.0791 / \mathrm{Re}^{0.25}\right) \\
& \mathrm{Re}=\rho \mathrm{VD} / \mu \\
& \Delta \mathrm{P}_{\mathrm{v}}=\text { Pressure drop through the vortex diode } \\
& \mathrm{D}=\text { hydraulic diameter } \\
& \mu=\text { fluid viscosity. }
\end{aligned}
$$

The pressure drop through the vortex diode for these calculations was assumed to be zero to estimate the approximate pressure drop that might be accommodated by the system. Table A2 shows results of these calculations. 
Table 2. Values calculated for natural circulation flow in the PB-AHTR

\begin{tabular}{lc}
\hline \multicolumn{1}{c}{ Parameter } & Value \\
\hline Number of DRACS & 8 \\
Number of pebble channels & 127 \\
Total core flow & $50 \mathrm{~kg} / \mathrm{s}$ \\
Core coolant & $\mathrm{FLiBe}$ \\
Core temperature rise & $28^{\circ} \mathrm{C}$ \\
Buoyancy head & $430 \mathrm{~Pa}$ \\
Core pressure drop & $260 \mathrm{~Pa}$ \\
Total heat rejected & $3300 \mathrm{~kW}$ \\
\hline
\end{tabular}


